Journal of Social Sciences (COES\&RJ-JSS)

ISSN (E): 2305-9249 ISSN (P): 2305-9494

Publisher: Centre of Excellence for Scientific \& Research Journalism, COES\&RJ LLC

Online Publication Date: $1^{\text {st }}$ April 2019

Online Issue: Volume 8, Number 2, April 2019

https://doi.org/10.25255/jss.2019.8.2.189.214

\title{
The Impact of Adapting the Jurisprudence of the Objectives of Sharia Controls \\ (Contemporary Financial Transactions as a Model) \\ Ahmad Taher
}

\begin{abstract}
:
The adaptation of the jurisprudence is a practical method of jurisprudence to judge the hew cases and matters. It can only be achieved after verifying the availability of its basic elements, including the objectives of Shari'a to deal with the new issues and developments in contemporary financial transactions. Therefore, this study aims to reveal the importance of the practice of adapting the jurisprudence to meet the challenges of the age and to show their role in practical cases.

Keywords:

Jurisprudence, Sharia Controls, Contemporary Financial Transactions

\section{Citation:}

Taher, Ahmad (2019); The Impact of Adapting the Jurisprudence of the Objectives of Sharia Controls) Contemporary Financial Transactions as a Model) ; Journal of Social Sciences (COES\&RJ-JSS), Vol.8, No.2, $\quad$ pp:189-214; https://doi.org/10.25255/jss.2019.8.2.189.214.
\end{abstract}


CHAPTER One) أثر التكييف الفقهي بمقاصد الثريعة وضوابطها(المعاملات المالية المعاصرة أنموذجاً)

1.1

1.2 يعتبر التكييف الفقهي أسلوباً من أساليب الاجتهاد الفقهي للحكم على الوقائع والقضايا المستجدة؛ فلا يصار إليه إلا بعد التحقق من توافر مقوماته وعناصره الأساسية، ومن بينها مراعاة مقاصد الثريعة لمعالجة الوقائع والمستجدات في المعاملات المالية المعاصرةغير المنصوص عليها، لذا تهدف هذه الدراسة للكثف عن دور المقاصد في تفعيل التكييف الفقهي من خلال إيضاح دورها في نماذج نطيقية. الكلمات المفتاحية: التكييف الفقهي، مقاصد الثريعة وضوابطها، المعاملات المالية المعاصرة

1.3

الحمد له حمداً كثيراً طيباً مباركاً فيه كما يليق بجلال اسمه وعظيم سلطانه، والصلاة والسلام على أشرف الخلق وحبيب الحق سيدنا محمد صلى الله عليه وعلى آله وصحبه وسلم، وبعد:

فإن معرفة الحِكم والغايات، والأسرار التشريعية التي احتوتها الثريعة هي حقيقة علم مقاصد الثريعة،

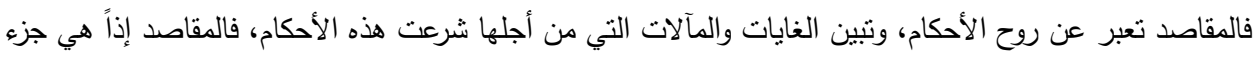

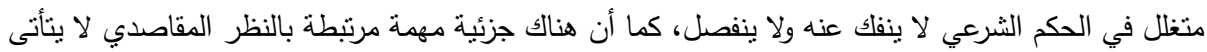
الاجتهاد بدونها وهو الفهم الواقعي الذي يحبطبالزمان والمكان والظروف والأحوال، فهو من أساسات تطبيق الاجتهاد المقاصدي والعمل المصلحي الذي يقتضيه فقه النصوص والقواعد الثرعية، لأن قصر الاجتهاد المقاصدي على محيط النصوص وفقهها بمنأى عن الواقع الذي يُعايثه ذلك الاجتهاد هو من أكبر العراقيل الكائنة في طريق المسيرة لتطبيق الأنيق المقاصد والمصالح الثرعية.

فالمقاصد غاياتها الكبرى هو السير بالثريعة مسيرة الخلود والبقاء ومنحها صفة العموم والثمول، الذي يكفل للبشرية الرحمة والهداية الربانية، لأن واقع الحياة كما هي السنة الإلهية متغير ومتقلب لايبقى على حالٍ ثابتة كما هو الحال نفسه في طبيعة المسائل الأجتهادية المعاصرة.

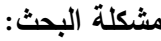

تكمن مشكلة البحث في الإفراط بالاجتهاد المقاصدي والنظر في المصالح الثرعية دون مراعاة للشروط الثرا والضوابط الموضوعة في هذا الثأن، ويعد هذا واحد من معوقات الععل الإنسلامي والمتنتل في تعدد الرؤى والتوجهات

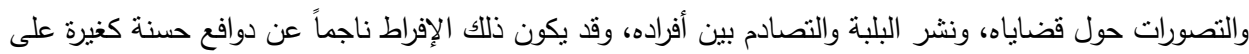
الدين أو محاولة لتحقيق اليسر الثرعي وإبداء السماحة الإسلامية. وقد يكون خارجا بنوايا سيئة من مجازفة فياستعمال المخارج والمسالك الثرعية في توهين أحكام الثرعية الثية الثينة والوصول إلى الغايات والأهداف الثخصية.

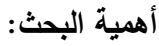

تكمن الأهمية في البحث عن مخرج للعمل بالضوابط التي تكفل للاجتهاد المقاصدي السير في طريق

الوسطية والاعتدال بين المحافظة على حرمة النصوص وأحكامها والعمل بمقاصدها وغايتها، حيث جدت مئات المسائل التي لم يرد فيها نص خاص يظهر حكمها الثرعي، ويمكن التوصل إلى حكمها المناسب من خلال مقاصد 
The Impact of Adapting the Jurisprudence of the Objectives of Sharia Controls ....

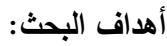

$$
\begin{aligned}
& \text { يهذف هذا البحث إلى تحقيف الغايات الآتيه: } \\
& \text { 1- - بيان أهمية التكييف الفقهي. } \\
& \text { 2- بيان أن الثريعة الربانية نزلت لتحقيق غايات ومقاصد عظيمة. } \\
& \text { 3- بيان ضوابط العمل بالمقاصد. } \\
& \text { 4- بيان كيفية التعامل مع مستجدات المعاملات المالية المعاصرة التي لم تحصل من قبل حيث لانص فيها ولا إجماع } \\
& \text { على حكمها. } \\
& \text { ومن هنا اخترنا البحث في هذا الموضوع ليكون بحثاً نطيقياً نعرض فيه نماذج عملية لأثر التكييف الفقهي } \\
& \text { بمقاصد الثرعية على بعض المعاملات المالية المعاصرة. } \\
& \text { وسنتتاول هذا الموضوع من خلال المبحثين التاليين: } \\
& \text { المبحث الأول: في مفهوم التكييف الفقهي. } \\
& \text { - - المطلب الأول: التكييف الفقهي في اللغة. }
\end{aligned}
$$

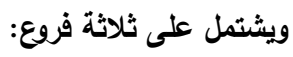

$$
\begin{aligned}
& \text { - - مالفرع الأول:الإطلاقات اللغوية لمادة [ كَيَّن]. } \\
& \text { - - - الفرع الثاني: التكييف في الإصطلاح اللغوي. } \\
& \text { - - المطلب الثاني: التكييف الفقهي في الاصطلاح باعتباره مركباً وصفياً. }
\end{aligned}
$$

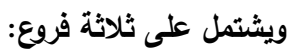

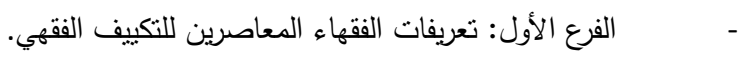

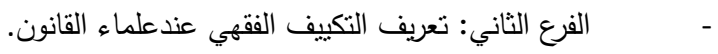

$$
\begin{aligned}
& \text { الفرع الثالث: التعريف المختار للتكييف الفقهي. لعربي. } \\
& \text { المطلب الثالث: المصطلحات ذات الصلة بالتكييف الفقهي. } \\
& \text { المبحث الثاني: في مقاصد الثريعة وأثرها في التكييف الفقهي للمعاملات المالية المعاصرة- . } \\
& \text { المطلب الأول: مفهوم مقاصد الثريعة وأنواعها. } \\
& \text { المطلب الثاني: ضواب الردّ إلى مقاصد الثريعة. } \\
& \text { المطلب الثالث:تطبيق الردّ إلى مقاصد الثريعة في تكييف القضايا والمستجدات المعاصرة. } \\
& \text { المطلب الرابع: آثار تطبيقات المقاصد على المعاملات المالية المعاصرة. } \\
& \text { المبحث الأول: مفهوم التكييف الفقهي المباري } \\
& \text { المطلب الأول: مفهوم التكييف الفقهي في اللغة: }
\end{aligned}
$$

إذا نظرنا إلى التكييف الفقهي نجده مكون من كلمنين النكييف والفقهي وكل كلمة لها تعريفها ومعناها من

حيث اللغة والاصطلاح هذا باعنبار كونه مركباً وصفياً ويطلق باعتباره لقباً على صفة معينة. وسوف بشنتمل هذا

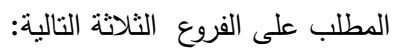

الفرع الأول: الإطلاقات اللغوية لمادة (كَيَقَ). 
مصدر (كَيَّنَ) وكَيَّفَ الثيه جعل له كيفية معلومة، وتكييف الثنيء صار لله كيفية من الكيفيات، و كَيَّنَ

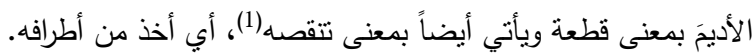

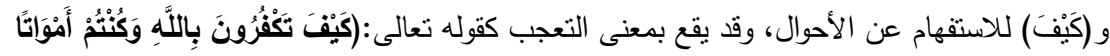

فَأَحْيَاكُمْم)

ومن الاستفهام عن الأحوال: كيف زيد؟ فيقال: صالح، فيستفهم بها عن حال الثيء وصفته مما بدرك

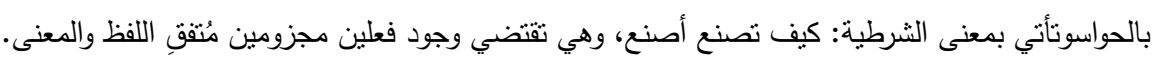

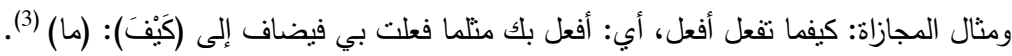

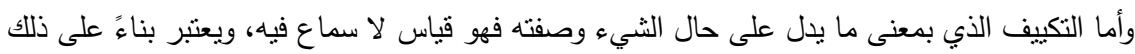

كلاماً مولداً، كما صرح بذللك أكثر من إمام من أئمة اللغة.

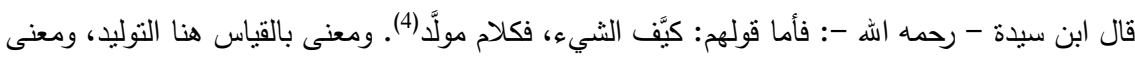

مولد أي: مستحدث.

وجاء عن الزبيدي- رحمه الله - قوله: التكييف اشنقاق من [كيف]: كيقته فتكيف فإنه قياس لا سماع فيه من

العرب(5). (15) (n)

ونخلص من ذلك إلى أن التكييف مصدر اصطناعي مولد من لفظ (كَّْفَ) وبالرغم من اختلاف فقهاء اللغة

في تعريف التكييف من حيث الألفاظ والمباني إلا أن هناك اتفاقا في المعنى وهو أن التكييف يعني حالة الثيء

وصفته.

الفرع الثاني: التكييف في الاصطلاح اللغوي:

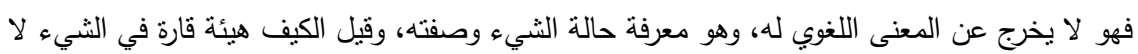

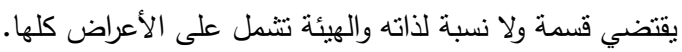
قوله: "قارة: احتراز عن الهيئة غير القارة كالحركة والزمان والفعل والانفعال.

(1) المعجم الوجيز، مجمع اللغة العربية، الطبعة الأولى - 1400هـ - 1980م، حرف كى 546/1.

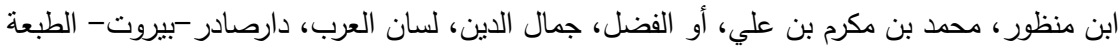
الثالثة1414هـ، فصل الكاف، 312/9 - 313.

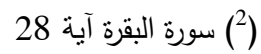

(3) الرازي، زين الدين أبو عبداله محمد بن أبي بكر بن عبد القادر الحنفي، مختار الصحاح، تحقيق، يوسف الثيخ

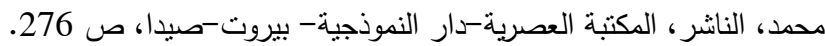

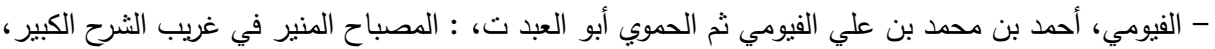
المكتبة العلمية - بيروت، مادة (كيف) 546/2.

- قلعه جي، محمد رواس قلعه جي، حامد صادق قتتيب، معجم لغة الفقهاء، الناثشر دار النفائس الطبعة الثانية

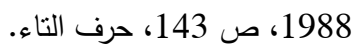
(4) ابن سيده، أبو الحسن علي بن إسماعيل بن سيده المربي، المحكم والمحبط الأعظم، تحقيق عبد الحميد هنداوي، الناثر دار الكتب العلمية، بيروت، الطبعة الأولى، 1421هـ - 2000م، 115/7. (5) (ابن سيده: المحكم والمحيط الأعظم ل15/7. 
The Impact of Adapting the Jurisprudence of the Objectives of Sharia Controls ....

وقوله: لا يقتضي قسمة يخرج الكم، وقوله: ولا نسبة يخرج الأعراض، وقوله: لذاته، ليدخل فيه الكيفيات

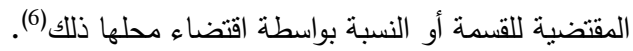

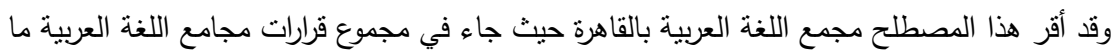
نصَّه: التكييف هو طبيعة المسألة التي تتتازعها القوانين لوضعها في نطاق طائفة من المسائل القانونية، التي خصها المشرع بقاعدة إسناد. وقالوا: النكييف اللاحق هو التكييف اللازم لإعمال القاعدة الموضوعية التي تعينها قاعدة الإسناد في قانون القاضي أو لإعمال قاعدة الإسناد الداخلي في القانون الأجنبي (7).

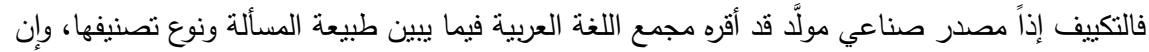
كان المجمع قد تناوله من الناحية القانونية إلا أنه قريب من المعنى المراد في استعمال الفقهاء المعاصرين للتكييف. المطلب الثاني: التكييف الفقهي في الاصطلاح باعتباره لقباً على صفة معينة:

يعتبر مصطلح (التكييف الفقهي) من المصطلحات القانونية الحادثة التي غلب استعمالها لاى الفقهاء المعاصرين ولم يكن هذا المصطلح معروفاً لدى أئمة الفقه خلال العصور الماضية، وإن كانوا قد باشروا هذا المصطلح بمعناه ومارسوه تطبيقاً.

ومن خلال استقراء بعض الكتب الفقهية وجد عند بعض فقهاء الإباضية استعمال لهذا المصطلح، ولكن في غير المراد به عند الفقهاء المعاصرين حيث يريدون بالتكييف أداء الفعل في الباطن من غير إظهار حدوث صوت أوضاه

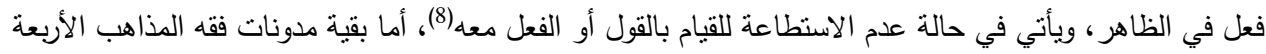
فلا يوجد استعمال لهذا المصطلح بالمعنى الذي يطلقه فقهاؤنا المعاصرون. ونظراً لأهمية التكييف الفقهي في التعرف على حكم المسألة المستجدة كان لزاماً من إعطاء حد مناسب يتميز به هذا المصطلح الثائع بين الفقهاء المعاصرون.

(6) البركتي، السيد محمد عميم الإحسان المجردي، التعريفات الفقهية معجم يشرح الألفاظ المصطلح عليها بين الفقهاء والأصوليين وغيرهم من علماء الدين رحمه الله تعالى، دار الكتب العلمية بيروت، ص 186. باب الكاف.

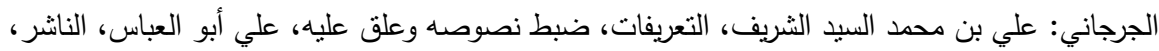
دار الطلائع-القاهره2008م، باب الكاف، فصل الياء. ص 185.

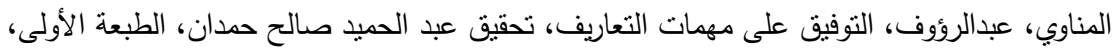

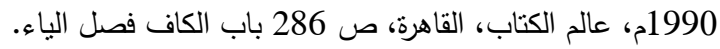
(7) (7) مجموع قرارات مجامع اللغة العربية. (7) أطفيش، محمد بن يوسف، شرح النيل وشفاء العليل ، مكتبة الإرشاد، جدة، دار الفتح، بيروت.

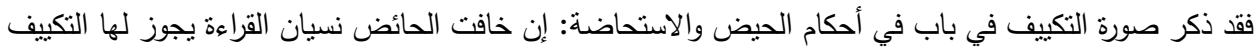

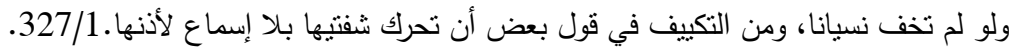

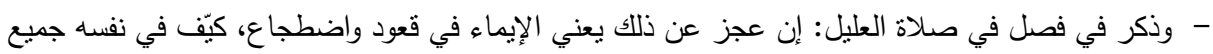
أعمالها، كأنه يعملها فكيف القراءة في نفسه، وإن أطاق القراءة ولم يطق الإيماء قرأ وكيف القيام والركوع

$$
\text { والسجود.101/2 وما بعدها. }
$$


وقبل بيان التعريف المختار للتكييف الفقهي، سوف أعرض بعض التعريفات التي ذكرها بعض أهل العلم المعاصرين وذلك لبيان فهم المراد من هذا المصطلح في الفروع الأربع التالية. الفرع الأول: تعريفات الفقهاء المعاصرين للتكييف الفقهي:

1. جاء في كتاب [معجم لغة الفقهاء] تعريف للتكيف الفقهي للمسألة، قيل فيه: "تحريرها وبيان انتمائها إلى أصل معين معتبر" (9).

وهذا التعريف جيد المعنى وواضح الدلالة على بيان المقصود من التكييف، وإن كان ينقصه بيان الخطوة

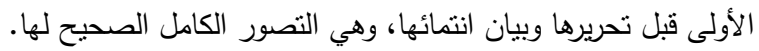

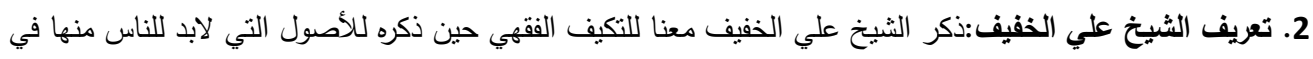

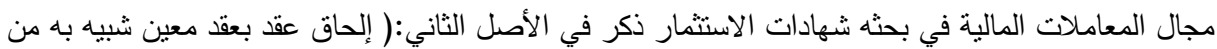

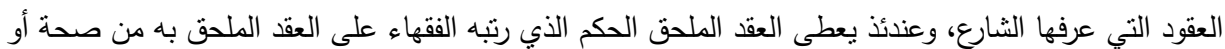

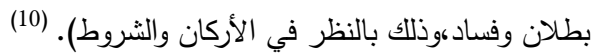
ويلاحظ على هذا التعريف أنه اقتصر التكييف الفقهي على المعاملات المالية: من عقود، وتصرفات، ولم يشتمل على بقية فروع الفقه؛ ولعل هذا الحصر في التعريف لكونه جاء في سياق بحث في الفي المعاملات المعات المالية

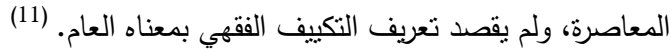
3. تعريف الدكتور محمد صلاح الصاوي:عرف الدكتور محمد صلاح الصاوي التكييف الفقهي بأنه: ( رد العملية المعاصرة إلى أصلها الثرعي، وإدراجها تحت ما يناسبها من العقود التي تولى الفقه الإسلامي صياغتها وتنظيم أحكامها، ليكون ذللك منطلقا للإصلاح والتقويم ). (12) كذللك بلاحظ على هذا التعريف ما لوحظ على التعرف الذي قبله باقتصاره التكييف على المعاملات المالية

$$
\text { دون غيرها من أبواب الفقه. }
$$

4.عريف فضيلة الثيخ عبد الله بن سليمان بن منيع:قال: (التكييف: بمعنى التساؤل بلفظ كيف، عن وجه إرجاع مسألة ما من المسائل المعاصرة إلى ما تتدرج تحته من المسائل الفقهية المعروفة لدى قدماء الفقهاء، وذلك بلفظ كيف ترجعها إلى ما تعتبر جزءا من جزئيات ذلك الأصل ). كذلك هذا التعريف جيد المعنى وواضح الدلالة على بيان المقصود من التكييف، غير أنه ينقصه بيان الخطوة

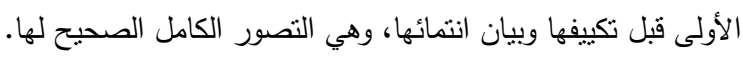

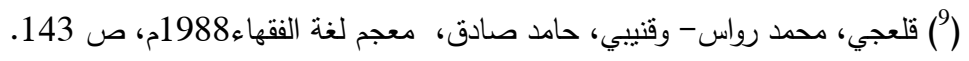

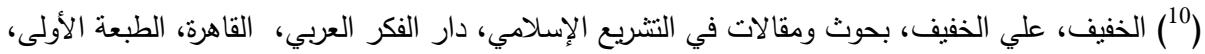
1431هـ -2010.رفع عبد الرحمن النجدي المبحث العاشر شهادات الاستثمار .ص 278.

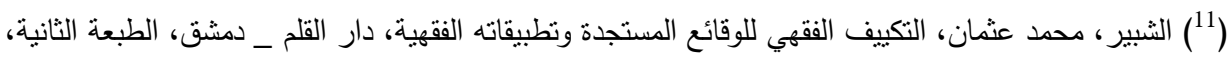

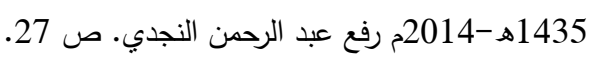

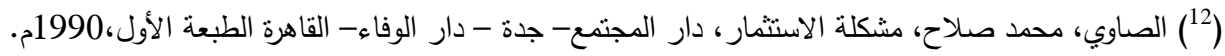

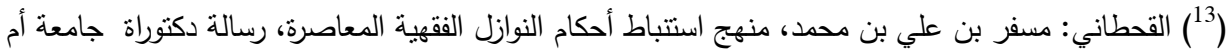

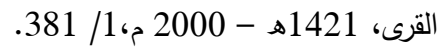


The Impact of Adapting the Jurisprudence of the Objectives of Sharia Controls ....

5. تعريف الاكتور الزيجاني:تصنيف المسألة تحت ما يناسبها من النظر الفقهي، أو يقال: هو ردّ المسألة إلى أصل من الأصول الثرعية.

$$
\text { وبين في شرحه للتعريف أن التكييف نوعان بسيط ومركب: }
$$

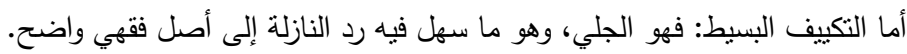

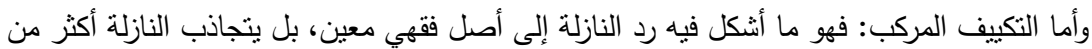

أصل. (14)

الفرع الثاني: تعريف التكييف الفقهي عندعلماء القانون:

ومن التعريفات التي تفيدنا في فهم مصطلح التكييف الفقهي تعريف علماء القانون لأن مصطلح (التكييف)

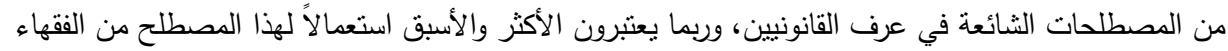

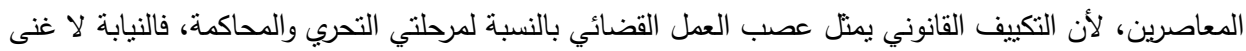
لها عن تكييف الجريمة وذلك لمعرفة النص الواجب النطبيق على الواقعة، كذللك فإن المحكمة المختصة التي تحال التهال

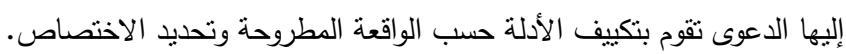

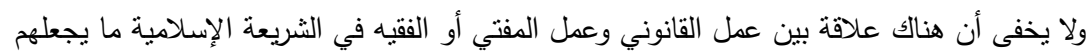

يتشابهون في طريقة عملهم كما في البحث عن علة الحكم، والاستقراء، وتحقيق المناط، والاسنتباط الفقهي، والاستدلال بشكل عام، وهذا ييرز العلاقة الوطيدة بين عمل القانوني وعمل المفتي والفقيه.

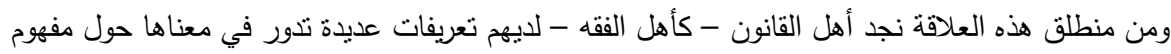
التكييف، فمن تلك التعريفات:

- - أن التكيف هو : بيان حكم النص القانوني الذي تخضع له الواقعة والذي يحكمها ويعاقب عليها.(15) -

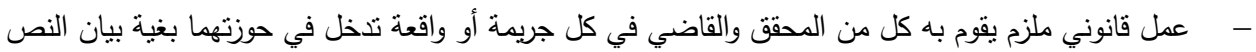

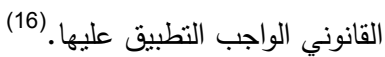
- ويؤكد على ذات المعنى جانب من الفقه المصري بقوله:(إن التكييف هو العلاقة بين الواقعة لتقدير القاضي والنص

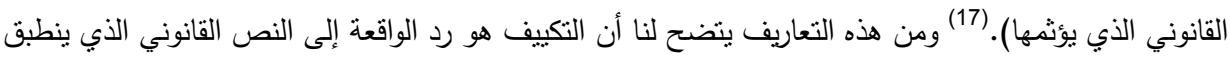

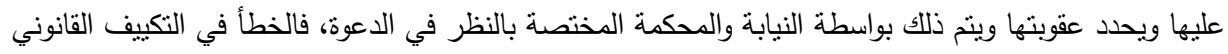
يترتب عليه خطأ في نطبيق النص القانوني على الواقعة. الفرع الثالث: التعريف المختار للتكييف الفقهي: بعد هذا العرض لتعريفات التكييف الفقهي نستطيع أن نختار تعريفاً مناسباً من وجهة نظر الباحث: ( التصور الكامل للواقعة وتحرير الأصل الذي تنتمي إليه ) (14) الجيزاني، محمد بن حسين، فقه النوازل ( دراسة تأصيلية تطبيقية ) دار ابن الجوزي،1427 هـ-2006م، $.49-47 / 1$

(15)- المرصفاوي، حسين المرصفاوي، الدعوى المدنية أمام الحاكم الجنائية، دار المعارف، 1964م، 456، 456.

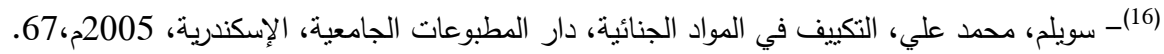

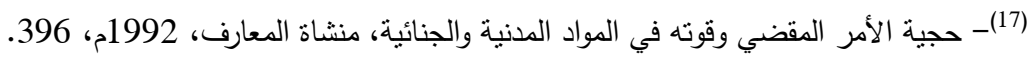


- التصوّر: هو حصول صورة الثيء في العقل، وإدراك الماهية من غير أن يحكم عليها بنفي أو إثبات(18)؛ فالتصور

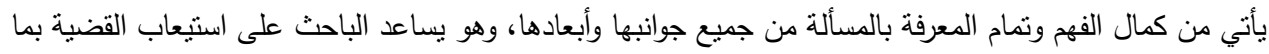

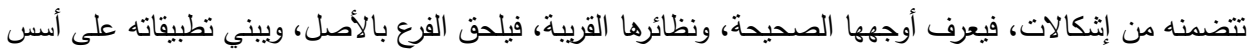
علمية، فيأتي حكمه فيها صحيحاً ونظره سليماً، ومن ثم فالتصور الفقهي يتضمن مرحلتين أساسيتين:

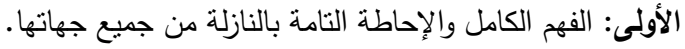
الثانية: إدراجها تحت أصلها الشرعي الذي تنتمي إليه. الكامل: وهو احتراز من النصوّر الناقص الذي لايوفي الواقعة حقَّها من الفهم والنظر ؛ لما يترتب عليه بالتالي من حكم إلبه مخالف ومجانب لحقيقة الأمر والواقع الصحيح.

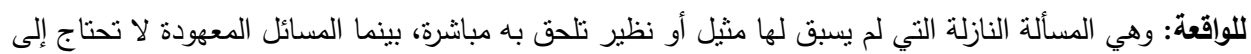
تكييف بقدر ما تحتاج إلى تحقيق لمناط المسألة في غالب أحيانها. والواقعة: لفظ عام لا بقتصر على نوع معين من أنواع الفقه الإسلامي، وإنما يشمل العبادات، والمعاملات، واتهات

والسياسة الثرعية، والقضايا الاجتماعية، والقضايا الطبية، وغيرها.

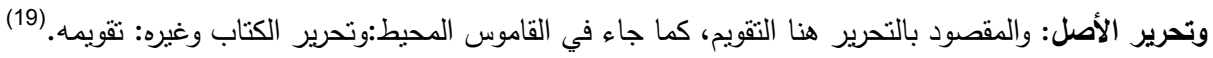

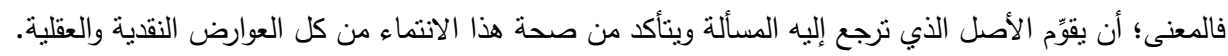

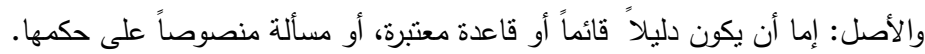
- - الذي تنتمي إليه: أي ترجع إليه من أجل الوصول إلى دكمها في الثرع.

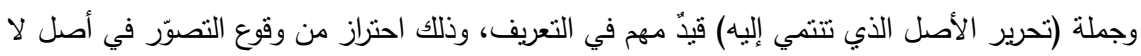

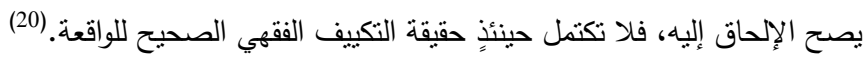

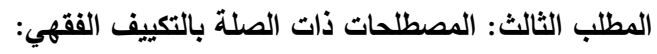

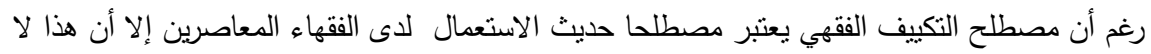
يعني أن الفقهاء القدامى لم يمارسوا عملية التكييف الفقهي، وإنما مارسوها تحت مسميات عدة وألفاظ مختلفة في الأبحاث الفقهية القديمة ومن هذه التسميات: 1- التصوّز أو التصوير.

التصور في اللغة: هو التخيل، يقال تصور الثيء أي تخيّله، واستحضر صورنه في ذهنه.(21)

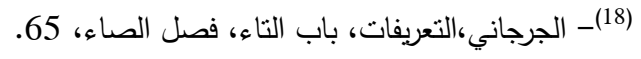

(19)- الفيروزآبادي، مجدالدين أبو طاهر محمد بن يعقوب، القاموس المحيط، تحقيق، مكتب تحقيق التراث في مؤسسة

الرسالة، بإثراف : محمد نعيم العرقسوس، الناشر ، موؤسسة الرسالة-بيروت- الطبعة الثامنة 1426هـ -

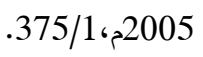

(20)- القحطاني، مسفر بن علي، منهج اسنتباط أحكام النوازل الفقهية المعاصرة، 248/1.

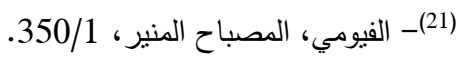

- السيوطي،عبدالرحمن بن أبي بكر جلال الدين، معجم مقاليد العلوم في الحدود والرسوم، تحقيق:محمد ابراهيم عبادة،

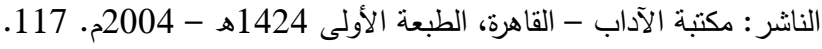


The Impact of Adapting the Jurisprudence of the Objectives of Sharia Controls ....

وفي الاصطلاح: هو حصول صورة الثيء في العقل، وإدراك الماهية من غير أن يحكم عليها بنفي أو أثبات(22). وجه الصلة بين التكييف الفقهي والتصوّر: أن التصور مرحلة تسبق التكييف بالنسبة للمسألة المستجدة، وبعتبر أساس التكييف، فإن كان التصوّر تاماً،

كان التكييف سليماً، وإلا فلا (23). ثانياً: التخريج وصلته بالتكييف الفقهي:

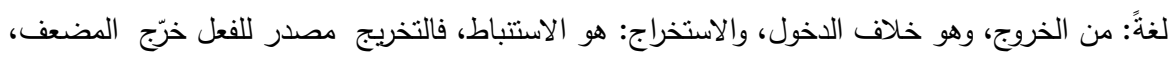
ومثاله خرَّج الثيء واستخرجه فإنها بمعنى استتبطه(24)؛ ذلك لأنّ (النّخريج) عملية إنفاذ ل ل( فرع) من دليله، وإظهاره له بعد أن كان مختقيا فيه، بالقاعدة الأصولية(25).

واصطلاحاً: لفظ التخريج استعمل في جملة من العلوم فيختلف استعماله عند أهل الحديث عنه عند الفقهاء

والأصوليين، وموضع بحثا هو استخدامه عند أهل فن الفقه والأصول عموما هو : نقل حكم مسألة إلى ما يشبهها،

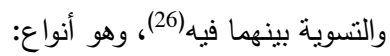

1- تخريج الفروع على الأصول: هو العلم الذي يبحث في علل أو مآخذ الأحكام الثرعية، لردّ الفروع إليها بياناً لأسباب

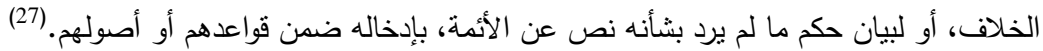

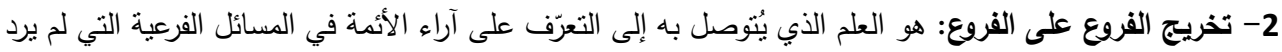

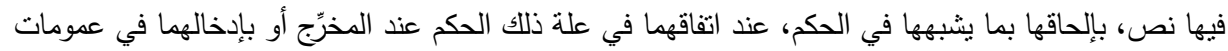

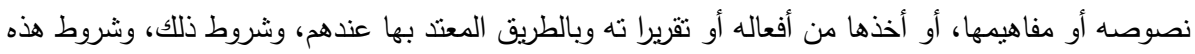

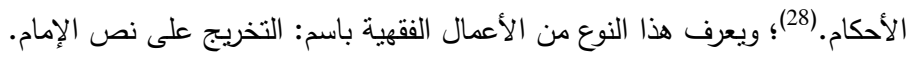
وجه الصلة بين التكييف الفقهي والتتريج:

(22) - الجرجاني، التعريفات، باب التاء، فصل الصاء، 65 الصناء

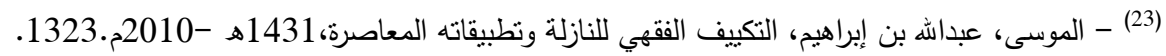
(24) ابن منظور، لسان العرب، باب الجيم فصل الخاء، 2/ 249، 239، الرازي: مختار الصحاح، باب الخاء مادة خرج، 89.

(25) - شوشان، عثمان بن محمد الأخضر ، تخريج الفروع على الأصول - دراسة تأريخية ومنهجية وتطبيقية -

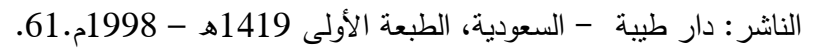

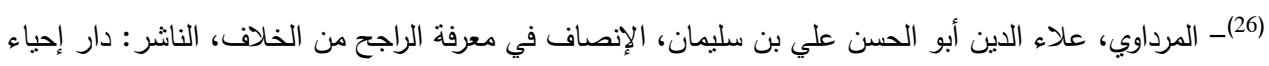
التزاث العربي،الطبعة الثانية. 6/1.

- آل تيمية، المسودة في أصول الفقه، تحقيق: محمد محي الدين عبد الحميد،النانر : دار الكتاب العربي.533. (27)- الباحسين، يعقوب بن عبدالوهاب بن يوسف، التخريج عند الفقهاء والأصوليين - دراسة نظربة نطبيقية نأصيلية

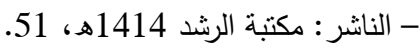
(28) - الباحسين، التخريج عند الفقهاء والأصوليين،187 الند، 1814 
يعتبر التكييف الخطوة الأولى والمرحلة الأساس التي يبنى عليها التخريج الصحيح، الموافق للادليل أو قول

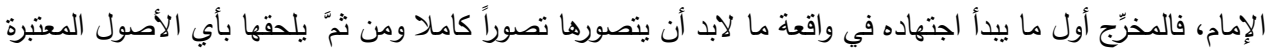
المشابهة لهاب(29).

ثُالثاً: تحقيق المناط وصلته بالتكييف الفقهي: بأني بيان تعريف تحقيق المناط لغةً واصطلاحاً كما يلي: باطئ أولاً: التحقيق والمناط في اللغة:

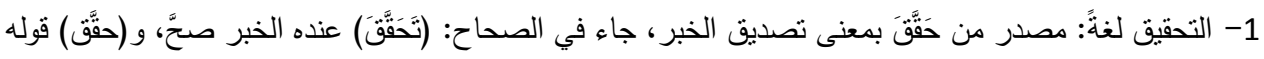

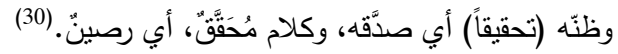

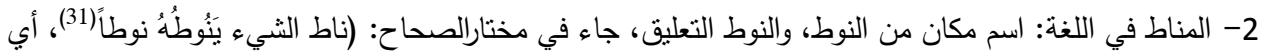

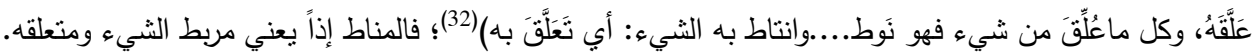
ثانياً: تعريف المناط اصطلاحاً:

الهناط اصطلاحاً بعني علة الحكم. جاء في المسنصفى:(اعلم أنَّا نعني: بالعلَّة في الشرعيات مَنَاطَ الحُكم إليه، أي:ماأضاف الثرع الحكم إليه، وناطه به، ونصبه علاطمة عليه اليه) (33). وقد اختلف الأصوليون في تعريف العلة اصطلاحاً على عدة هذاهب ووجوه، وهي إجمالاً تعني: ([الوصف]

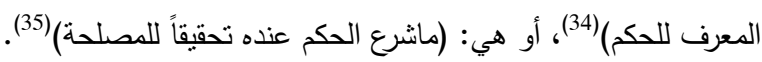
ثالثاً: تعريف تحقيق المناط اصطلاحاً:

(29) - الفتوحي، تقي الدين أبو البقاء محمد بن أحمد بن عبد العزيز، شرح الكوكب المنير، تحقيق: محمد الزحيلي ونزيه حماد، الناشر: مكتبة العبيكان. الطبعة الثانية 1418هـ - 1997م. 4 - 469.

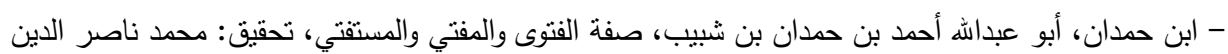

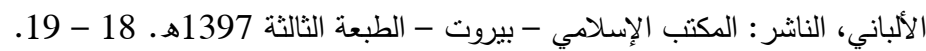

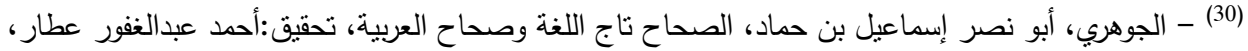
النانر : دار العلم للملايين - بيروت، الطبعة: الرابعة 1407هـ -1987م.باب القاف حقق، 1461/4.

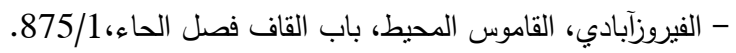

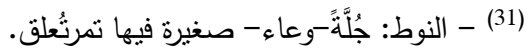

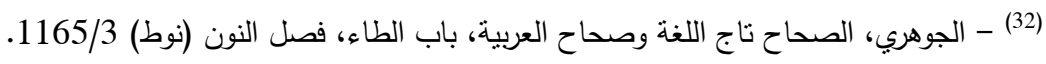

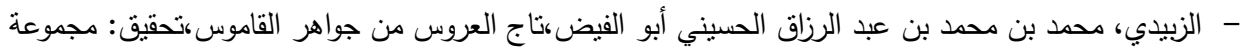

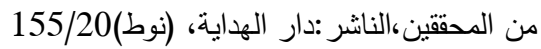
- الفيروزآبادي، القاموس المحيط، باب الطاء فصل النون،418/7. (33) - الغزالي، المستصفى 281. (34) - السبكي، تقي الدين أبوالحسن علي بن عبد الكافي، الإبهاج في شرح المنهاج، (منهاج الوصول إلى علم الأصول للقاضي البيضاوي)، الناشر: دار الكتب العلمية - بيروت 1416هـ -1995م.

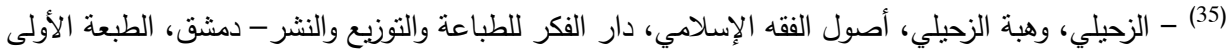

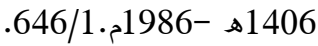


The Impact of Adapting the Jurisprudence of the Objectives of Sharia Controls ....

النظر في معرفة وجود العلة في آحاد الصّور، بعد معرفتها في نفسها، وسواء كانت معروفة بنص، أو

إجماع، أو استنباط(36)

يقول الإمام الثاطبي- رحمه الله- في تعريف تحقيق المناط: أن يثبت الحكم بمدركه الثرعي لكن يبقى النظر

في تعيين محله.

ثم قال - رحمه اله-- ويكفيك من ذلك أن الثريعة لم تتص على حكم كل جزئية على حدنها، وإنما أنت بأمور

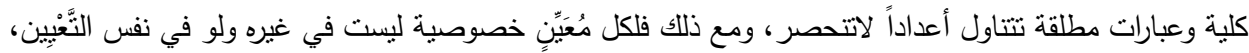

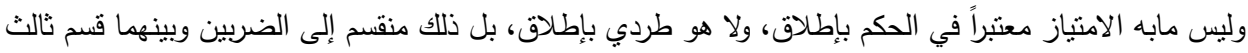

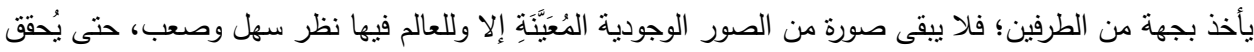

تحت أي دليل تدخل، وهذا كله بيّن لمن شدا في العلم (37).

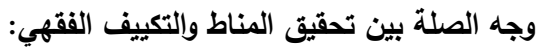

يتنين لنا مما مضى ذكره وجود علاقة بين النكييف الفقهي وتحقيق المناط، فتكون مهمة المجتهد في تحقيق المناط تطبيق الكلي على جزئياته لوجود الثبه من خلال المناط المنصوص وجلئ أو المجمع عليه، وتحقيق وجود الثبه بين

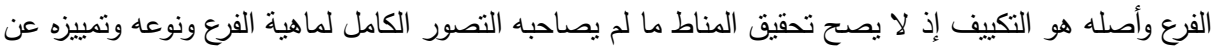

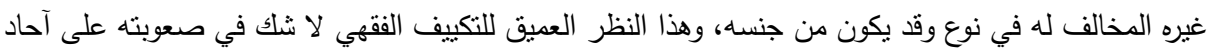
المجتهدين وأنصاف العلماء إلا من شدا في العلم- كما قال الثاطبيي- رحمه الهـ-(38).

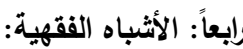

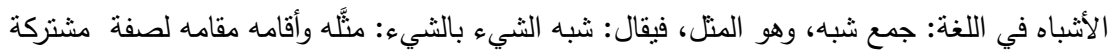

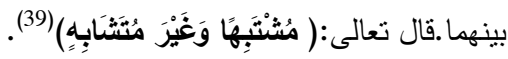

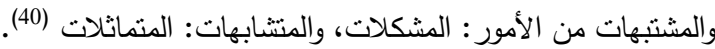

(36) - الآمدي، أبو الحسن سيدالدين علي بن أبي علي بن محمد بن سالم الثعالبي، الإحكام في فصول الأحكام،

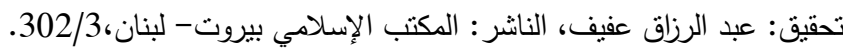

- ابن أمير حاج: أبو عبداله شمس الدين محمد بن محمد ، التقرير والتحبير، الناشر ، دار الكتب العلمية، الطبعة الطبراف

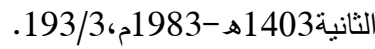
- الزحيلي، أصول الفقه الإسلامي $1403 / 1$ -

(37) - الثناطبي، إبراهيم بن موسى بن محمد اللخمي الغرناطي، الموافقات، تحقيق: أبو عبيدة مشهوربن حسن آل آل الرئ

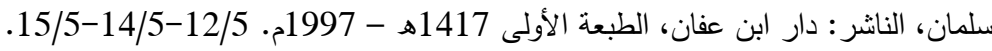
(38) - حمادي، إدريس، المنهج الأصولي في فقه الخطاب، نشر المركز الثقافي العربي - الدار البيضاء، الطبعة

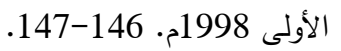

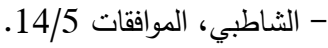
. (39) - سورة الأنعام الآية

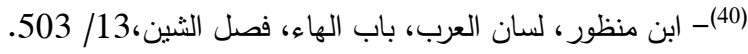

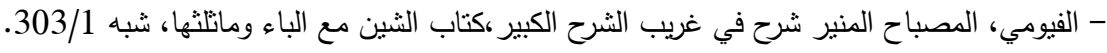

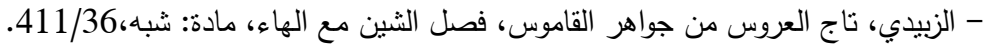


والأشباه في الاصطلاح: المسائل الفقهية التي تشبه بعضها بعضاً في المعنى لجامع بينها، وتشترك في

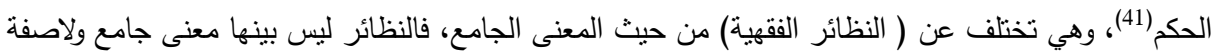
مشتركة؛ وبالتالي تختلف في الحكم. وتعرف النظائر الفقهية بأنها: المسائل التي تثبه بعضها بعضاً في الظاهر وتختلف في الحكم لأمور خفية أدركها الفقهاء بدقة أنظارهم(42). وأصل تسمبة هذا العلم بالأثباه يمكن تلمسه من خلا كتاب عمر بن الخطاب- رضي الله عنه- إلى أبي موسى الأشعري.

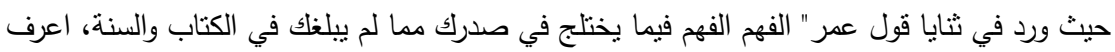

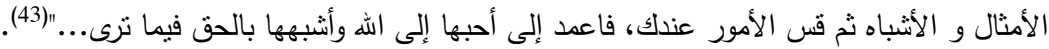

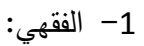

2- المشابهة لاتشتلزم المماتلة، فلا يلزم أن يكون شبه الثيء مماثلاً له، والنظير قد لايكون مشابهاً، وحاصل

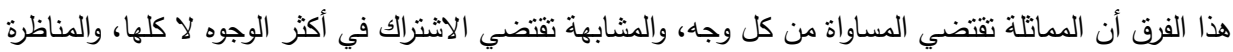
تكفي بعض والوجوه ولو وجهاً واحداً، يقال هذا نظير هذا في كذا، وإن خان خالفه في سائر جهاتها ( ).

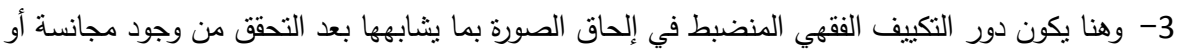
مشابهة في طبيعة كل منهما وذلك لإحاق الواقعة بالأصل الفقهي الذي خصه الثرع بأوصاف فقهية وإنزال نلك داف

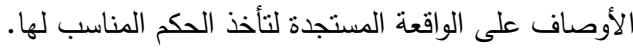
المبحث الثاني: مقاصد الثريعة وأثرها في التكيف الفقهي للمعاملات المالية المعاصرة 5- المطلب الأول: مفهوم مقاصد الثريعة وأنواعها. 6- تعريف مقاصد الثريعة:

(41)- السيوطي، جلال الدين عبدالرحمن، الأثباه والنظائر في قواعد وفروع الثافعية، تحقيق، محمد محمد تامر -

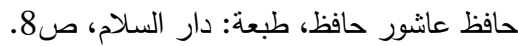

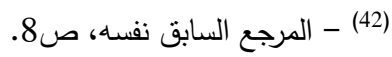

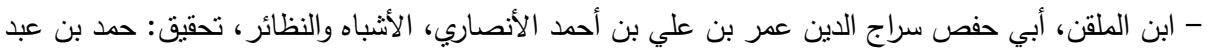

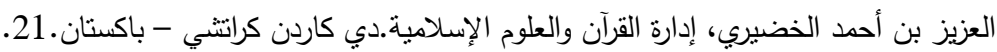

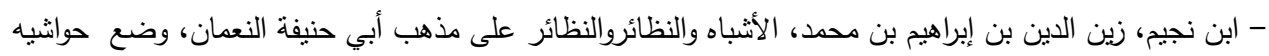

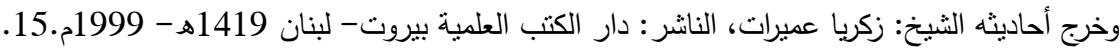
(43) - الدارقطني، أبو الحسن علي بن عمر بن أحمد بن مهدي بن مسعود بن النعمان بن دينار البغدادي، سنن الدار

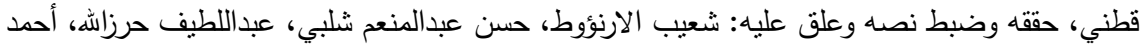

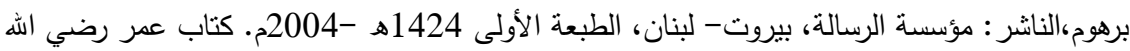

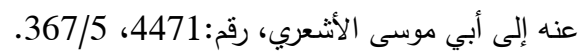
- البيهقي، أحمد بن الحسن بن علي بن موسى الخسروجردي الخراساني، السنن الكبرى، تحقيق: محمد عبدالقادر عطا، النانر : دارالكتب العلمية، بيروت - لبنان، الطبعة الثالثة 1424هـ - 2003م. باب مايقضي به به بـاني القاضي ويفتي به المفتي، رقم: 197/20347،10. 
The Impact of Adapting the Jurisprudence of the Objectives of Sharia Controls ....

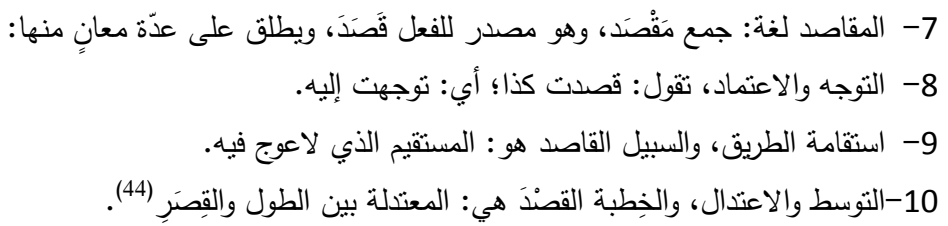

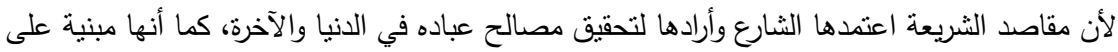

الاستقامة، والتوسط الذي لا إجحاف فيه ولا إسراف.

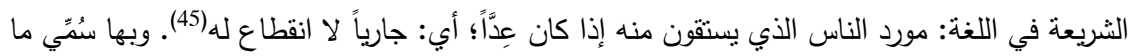

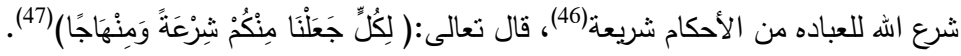
المقاصد الثريعة من جهة كونها علماً على هذا الفن المعيّن:

- عرفها الطاهر بن عانشور - رحمه الله- بقوله: المعاني والحِكَم الملحوظة للثشارع في جميع أحوال التشريع

أو معظمها، بحيث لا تختص ملاحظتها بالكون في نوع خاص من أحكام الثريعة(48).

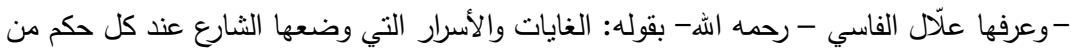

أحكامها (49).

أنواع المقاصد: لمقاصد أنواع متعددة باعتبارات مختلفة. أولا: مقاصد الثريعة من حيث صدورها قسمان:

أ- مقاصد الثارع: وهي المقاصد التي قصدها الثارع بوضعه الثريعة، وهي تتمثل إجمالاً في جلب المصالح ودرء

المفاسد في الدارين.

ب- مقاصد المكلف: وهي المقاصد التي يقدها المكلف في سائر تصرفاته، اعنقاداً وقولاً وعملاً، والتي تفرق بين صحة

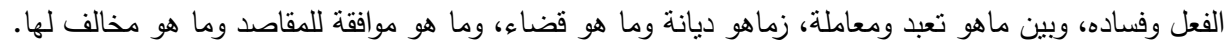
ثانياً: مقاصد الثرية باعتبار مدى الحاجة إليها ثلاثة أقسام:

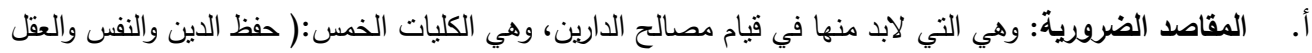

والنسل والمال)

$$
\begin{aligned}
& \text { (44)- الرازي، مختار الصحاح،ص254/1.مادة (ق ص د ). }
\end{aligned}
$$

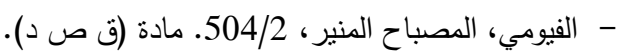

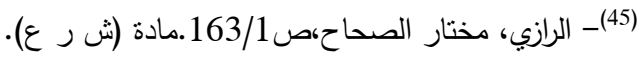

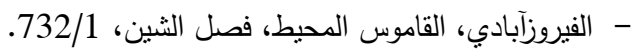

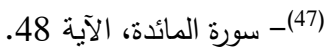

(48)- ابن عانشور ، محمد الطاهر، مقاصد الثريعة الإيلامية، تحقيق: محمد الطاهر الميساوي، الناشر : دار النفائس-

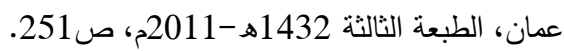

(49)- الفاسي، علّال الفاسي، مقاصد الشريعة ومكارمها، الناشر : دار الغرب الإسلامي، الطبعة الخامسة 1993م،

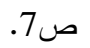


ب. المقاصد الحاجية: وهي التي يحتاج إليها للتوسعة ورفع الضيق والحرج والمشقة، ومثالها: الترخص في إباحة الطيبات، والتوسع في المعاملات المشروعة.

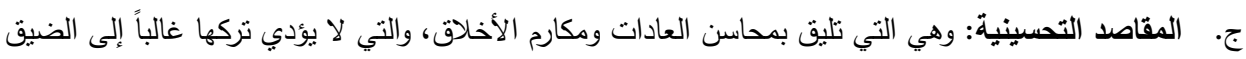
والمشقة، كالآداب العامة، المنوطة بالضيافة والأكل وقضاء الحاجة وستر العورة والطهارة، وحسن العشرة الزوجية، والوفاء بالعهود والمواثيق وغيرها. ثالثاً: المقاصد باعتبار تعلقها بعموم الأمة وخصوصها ثلاثة ألقاء أقسام:

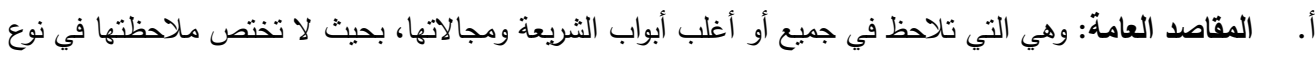

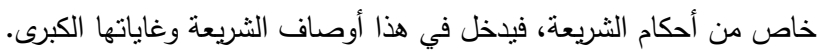

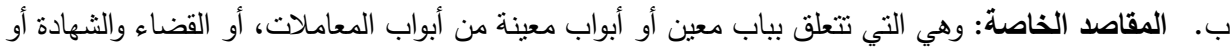

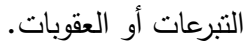
ج. المقاصد الجزئية: وهي علل الأحكام وحِكَها وأسرارها رابعاً: المقاصد باعتبار حظ المكلف وعدمه قسمان: أ. المقاصد الأصلية: وهي ليس فيها حظظ ظاهر للمكلف ومثالها، أمور التعبد والامتنال غالباً. ب. المقاصد التبعية: وهي التي فيها حظ ظاهر للمكلف ومثالها: الزواج والبيع(50). المطلب الثاني: ضواب الردّ إلى مقاصد الثريعة.

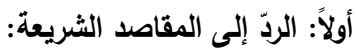

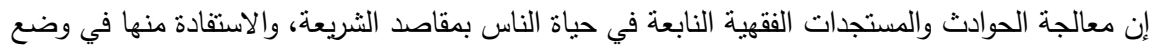

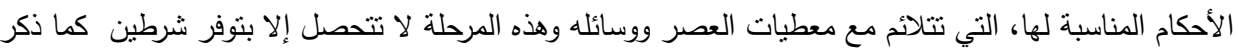
ذللك الإمام الثناطبي وهما: أ- - فهم مقاصد الثريعة على وجه الكمال.

ب- القدرة على الاستتباط منها وإنزالها منازلها في متقلبات العصر ومتغلغيراته. (51)

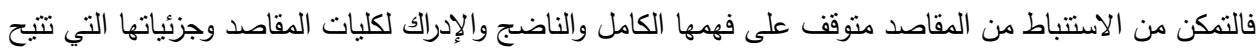
للمجتهد النظر والتمرس في القضايا والمستجدات الفقهية المعاصرة؛ فكانت المقاصد من أقرب الطرق وأخصرها لمعرفة الإنة

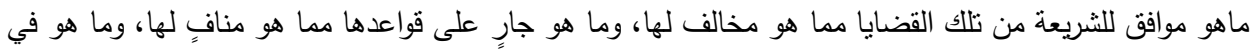

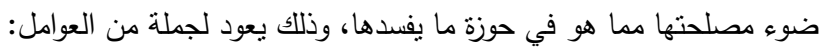

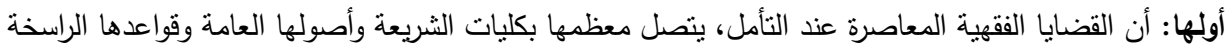

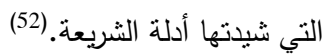

(50)- الخادمي، نورالدين مختار ، الاجتهاد المقاصدي- حجيته- ضوابطه- مجالاته، الناشر : وزارة الأوقاف والثنؤون

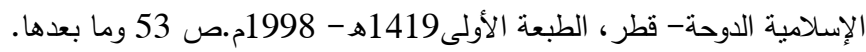
(51) - الثاطبي: الموافقات، 41/5-42) (52)- الهويريني: وائل بن عبد الله بن سليمان، المنهج في استتباط أحكام النوازل، مكتبة الرشد ناثشرون، الطبعة

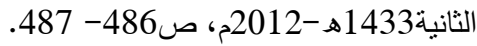


ثانيها: أن تصرف المجتهد في موارد الاجتهاد يقع على أنحاء، منها: إعطاء الحكم لحادثة لا نصّ في خصوصها، ولا

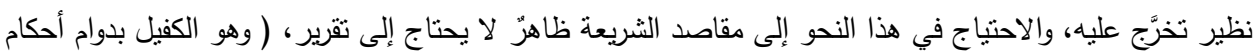

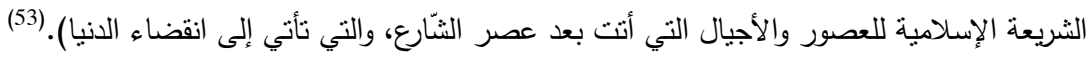

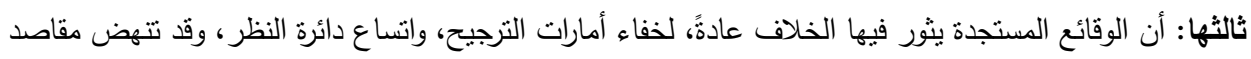

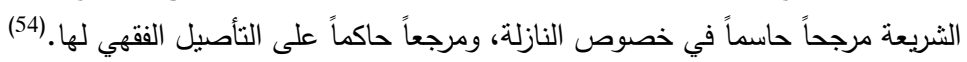
ثانياً: ضابط الرد إلى مقاصد الثريعة:

إن الضوابط للاجتهاد المقاصدي بمثابة الحدود التي لا يصح للمجتهد تجاوزها وتخطيها، ومعرفتها والقدرة

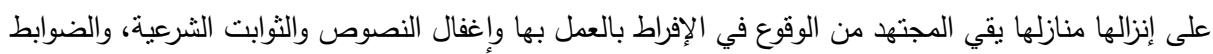

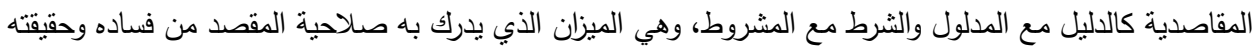
من توهمه، واعنباره مصلحيته من عدمه، وبها تصبح الثريعة مؤهلة لمواكبة المستجدات الفقهية ومواجهة التمتغيرات

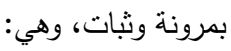
أولاً: ضابط التحقى من المقصدية: وثبات وهي:

يشترط في المجته الناظر في النوازل أن يتحقق من المقصود الثرعي للحكم الذي ناط به اجتهاده؛ لأنه

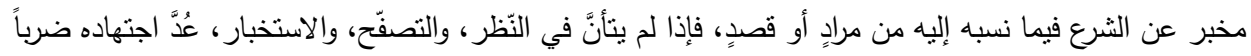

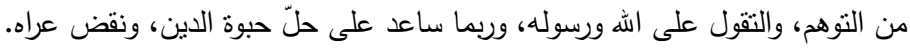

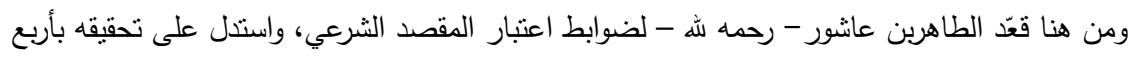

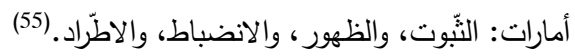

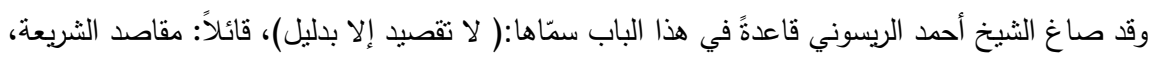

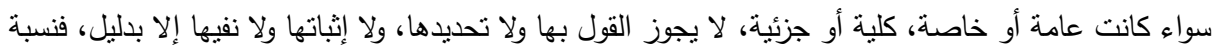

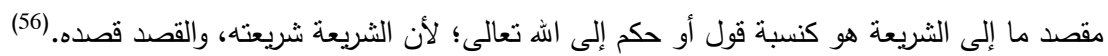
ثانياً: ضابط الموازنة بين الكليات والجزئيات:

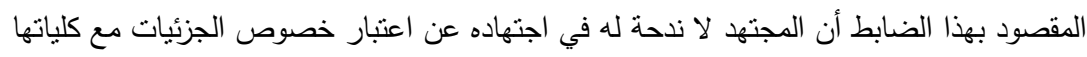

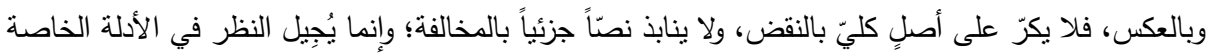

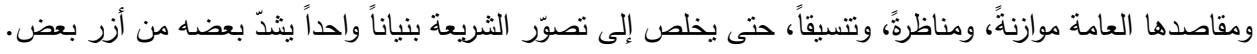

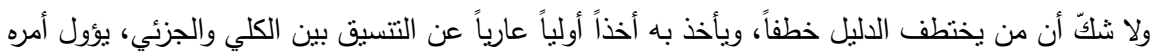

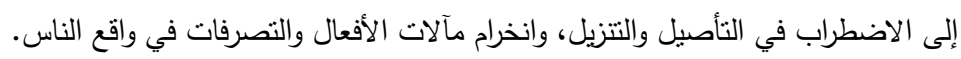

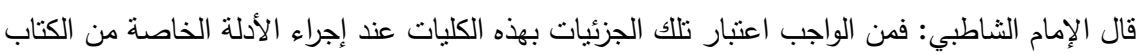

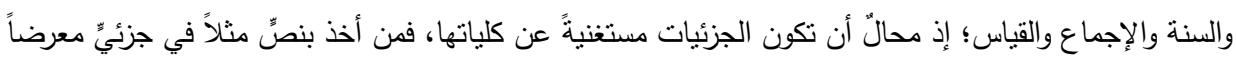

(53)- ابن عانشور : محمد الطاهر ، مقاصد الثريعة الإسلامية، ص184.

(54)- الريسوني: قطب، صناعة الفتوى في القضايا المعاصرة معالم وضوابط وتصحيحات، دار ابن حزم، الطبعة الإنة

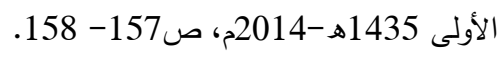

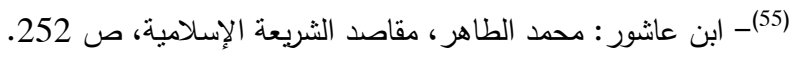

(56)- الريسوني: أحمد، الفكر المقاصدي قواعده وفوائده، منشورات جريدة الزمن - الدار البيضاء 2500، 2000م، ص صل 59. 
عن كليِّه فقد أخطأ، وكما أن من أخذ بالجزئي معرضاً عن كليّهِ فهو مخطىء؛ كذللك من أخذ بالكليٍّ معرضاً عن جزئيّه. (57) ثالثاً: ضابط مراعات رتب المقاصد:

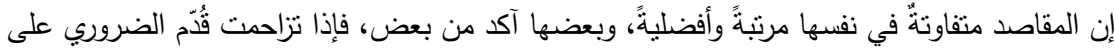

الحاجي، والحاجي على التحسيني، ومكمّل الضروري على الحاجي، ومكمّل الحاجي على التحسيني، وهكذا.....(58)،

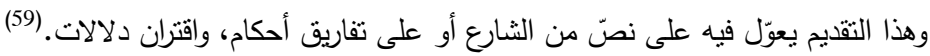

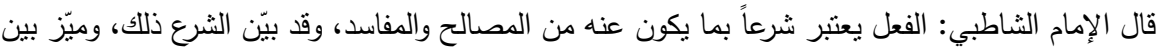

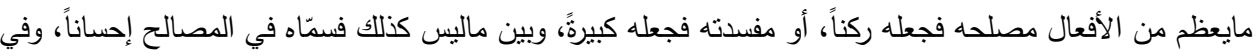
الدفسدة صغيرةً. وبهذه الطريقة يتميّز ما هو من أركان الدين وأصوله، وما هو من فروعه وفصوله، وذلك على مقدار المصلحة او المفسدة. (60)

المطلب الثالث: تطبيق الردّ إلى مقاصد الثريعة في تكييف القضايا والمستجدات المعاصرة:

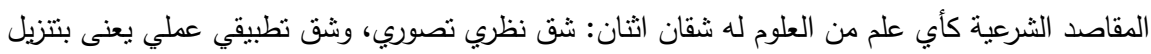

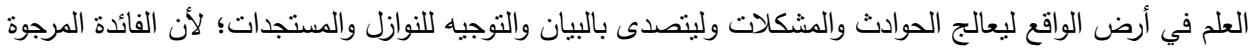
هي تأكيد الصفة النطبيقية والناحية العلمية لعلم المقاصد، إذ المقاصد- كما هو معلوم- ليست جملة من النظريات المركوزة في الذهن فحسب، بل هي مسلك عملي ميداني يخوض الواقع ويعالج مشكلاته ويقام له الحلول والبدائل والمخارج الصالحة والمصلحة، وخاصة في مجال المعاملات الماية المعاصرة، وفيما يأني نبين طائفة من التطبيقات ولئات

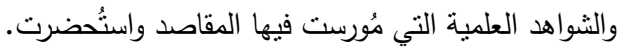

مسألة: [الأسهمم] تمثل الأسهم رأس مال الثركة المساهمة، فلو نُص في وثيقة السهم على أنه غير قابل للتناول والتصرف فيه

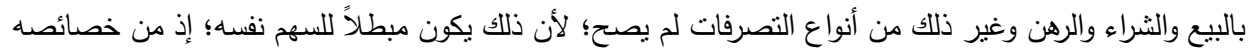

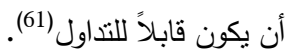

ووجه ذلك: أن النص على أن السهم غير قابل للتداول شرط فيه، والثروط مكملات لما اثترطت فيه، والمكمل لا بعتبر إذا أدى إلى إبطال ما كمله، وهو هنا مبطل لما كمله فلا يعتبر، كما لو انشترط البائع على المشتري فئه

$$
\text { (57) - الثناطبي: الموافقات، } 13 \text { / } 174 .
$$

(58)- المزيني: خالد بن عبداله بن علي، الفتيا المعاصرة دراسة تطييقية في ضوء السياسة الثرعية، النانشر : دار بن الني

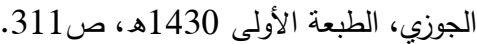

$$
\begin{aligned}
& \text { (59) - الغزالي: المستصفى،179/1. } \\
& \text { (60)- الثناطبي: الموافقات، }
\end{aligned}
$$

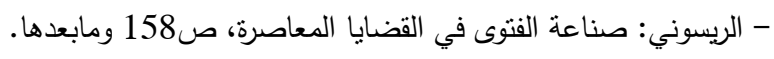

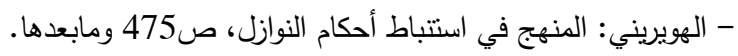

(61)- الثبير : محمد عثمان ،المعاملات المالية المعاصرة في الفقه الإسلامي، الناشر : دار النفائس، الطبعة السادسة

$$
\text { 1427هـ 2007م، ص199 (1927. }
$$


أن لا يبيع السلعة ولا يهبها أو يرهنها، فإن الثرط لايصح؛ (لأن الملك سبب لإطلاق التصرف)(62).ومن مقاصد

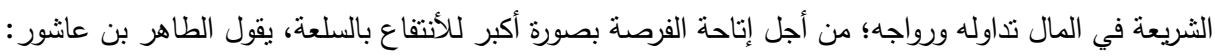
(والمقصد الثرعي في الأموال كلها خمسة أمور : رواجها، ووضوحها، وحفظها، وثباتها، والعدل فئها. فالرّواج: دوران المال بين أيدي أكثر من يمكن من الناس بوجه حق، وهو مقصد شرعي عظيمال....... (63).

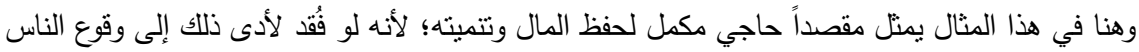

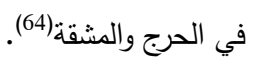

مسألة:: الصكوك الإسلامية]

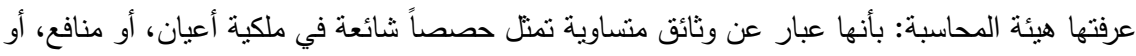

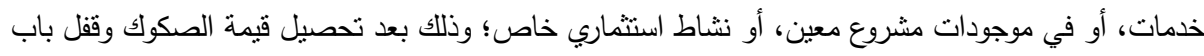

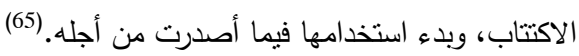

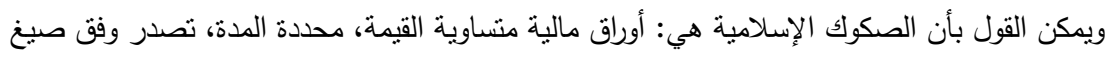

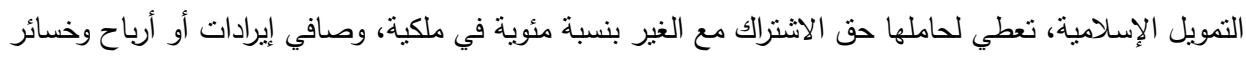

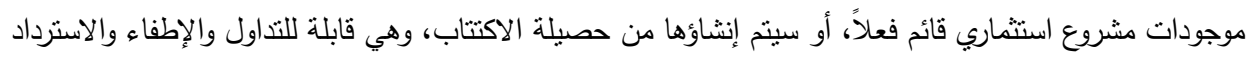

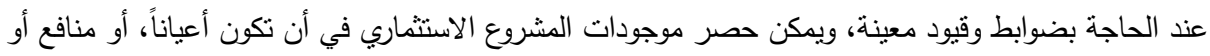

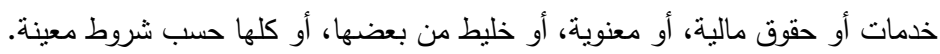

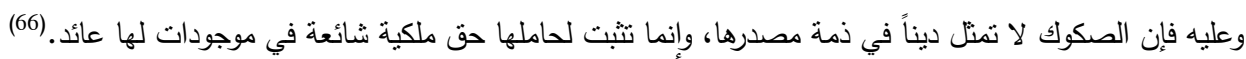

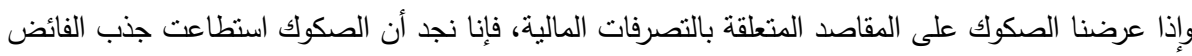

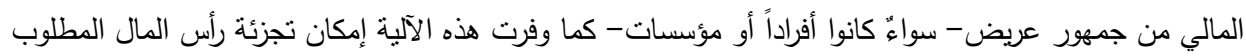

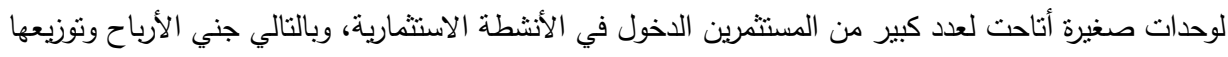

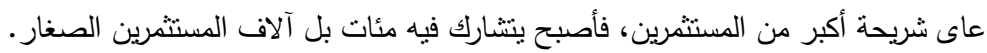

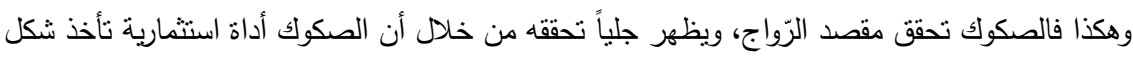
المشاركة. (67)

(62)- ابن قدامة: أبو محمد موفق الدين عبداله بن أحمد بن محمد ، المغني، الناشر : مكتبة القاهرة 1388هـ -

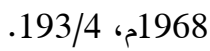

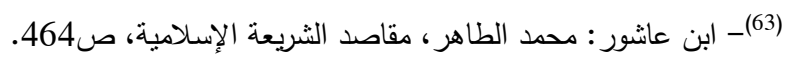

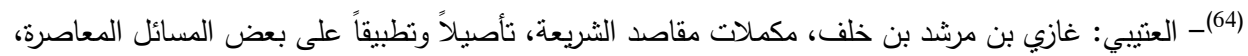

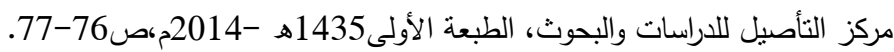

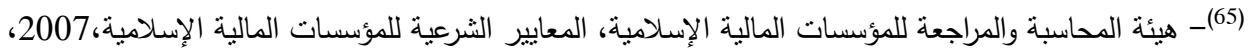

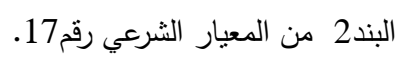

(66)- سليمان ناصر ، ربيعة بن زيد: إدارة مخاطر الصكوك الإنسلامية دراسة نطبيقية على الصكوك الحكومية

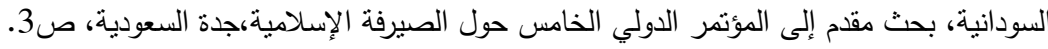


إذا نظرنا إلى المعاملات المصرفية المعاصرة وجدنا كل المصارف تقدم خدمة الصرف الآلي، وما ذلك إلا لإلا

تلبية لنقديم التقنية ومنطلبات السوق، حتى أنك لا تكاد تجد مصرفاً في العالم إلا ولديه هذه الخدمة. وتختلف المصارف بعضها على بعض في التعامل بالصرف الآلي، فبعض المصارف لا تثقاضى عُملات

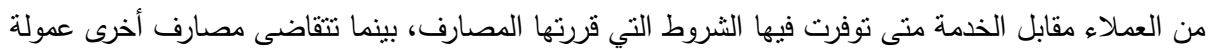
معينة مقابل هذه الخدمة.

إذا تقاضت المصارف عمولة من العملاء مقابل خدمة الصرف الآلي فهذا جائز شرعاً، وهو من باب الإجارة،

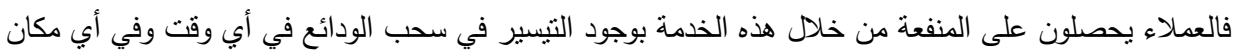

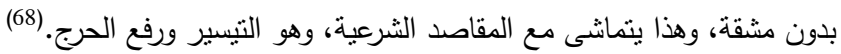

مسألة:[ الحوالات النقدية الخارجية والداخلية]

تقدم المصارف- التقليدية والإسلامية- خدمة التحويلات النقدية الخارجية والداخلية، وهي تعتبر من أهم

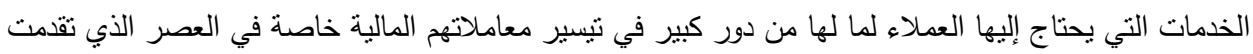

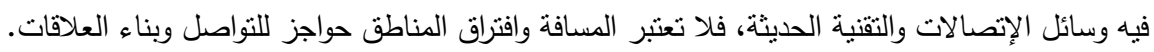

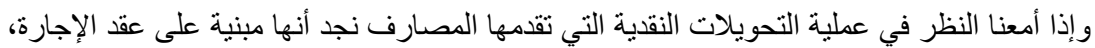

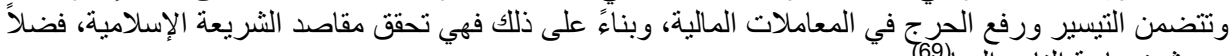

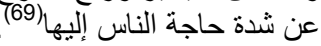

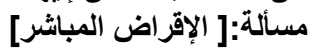

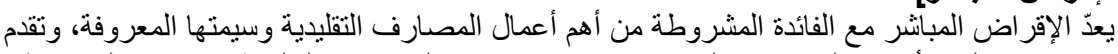

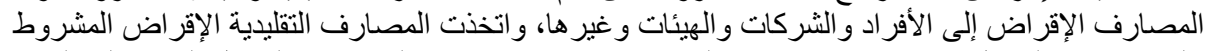

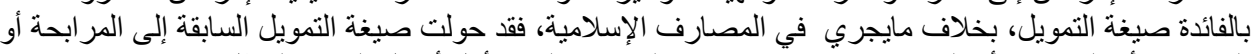

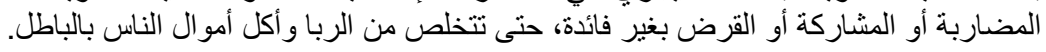

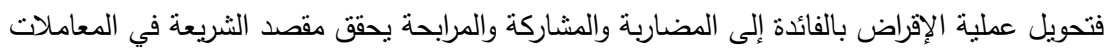

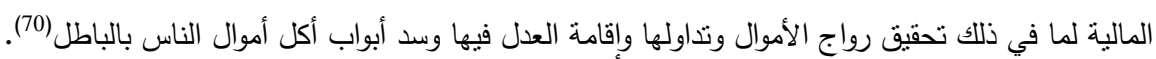
المطلب الرابع: آثار تطبيقات المقاصد على المعاملات المالية المعاصرة.

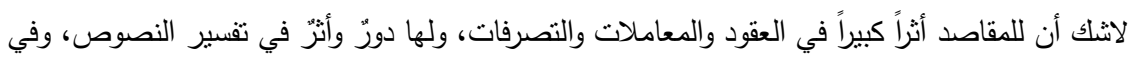

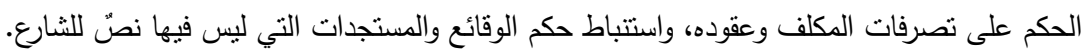

[والمقصد الأصلي في المعاملات المالية هو اعتبار مآلات الأفعال ومقاصد العقود ومعانيها لا ألفاظها ومبانيها].

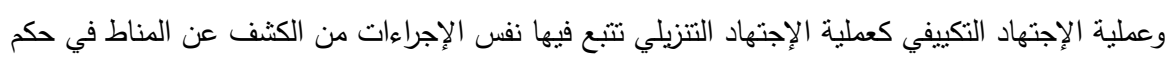

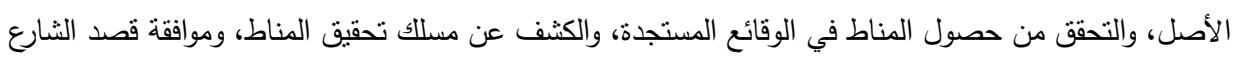

(67)- بشناق: أحمد، دور مقاصد الثريعة في تطوير صيغ التمويل الإسلامي، بحث مقدم إلى المؤتمر العلمي الدولي

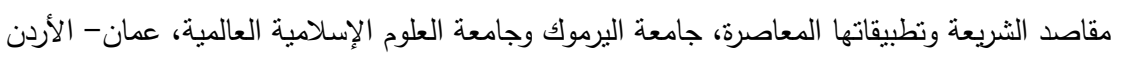

$$
\text { 23-23 كانون الأول2013،24-25. }
$$

(68)- عبدالرحيم، مقاصد الثريعة وتطبيقاتها في المعاملات المصرفية المعاصرة، رسالة ماجستير من جامعة المدينة

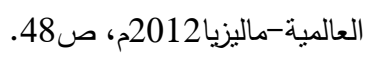

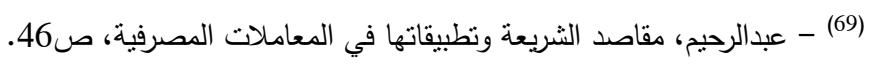

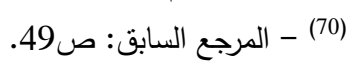


لقصد المكلف، والنظر في المآلات مع مراعاة فقه الواقع وملابسانه، ولايخلو أي إجراء من هذه الإجراءات من حضور

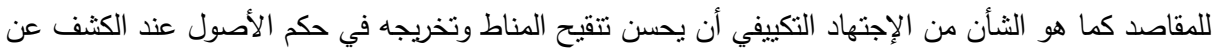

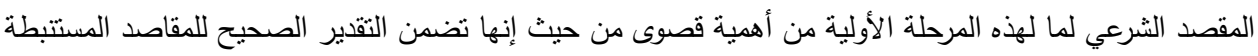

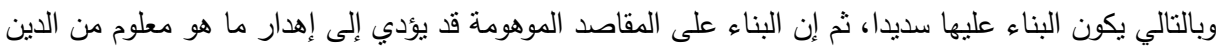

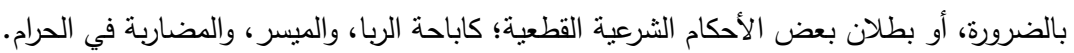

الخاتمة

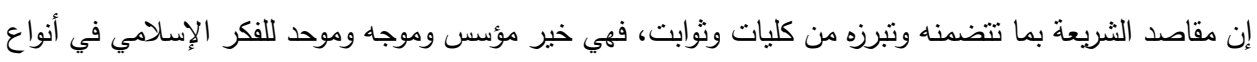

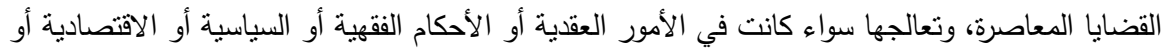

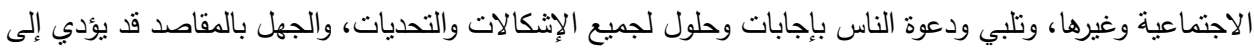

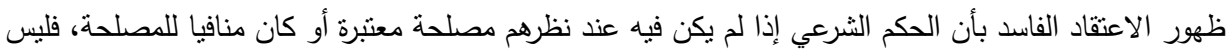
حكما شرعيا.

إن المقاصد الثرعية من المعطيات الضرورية الني يعاد إليها في تكييف الأحكام الثرعية وفق الوقائع المستجدة

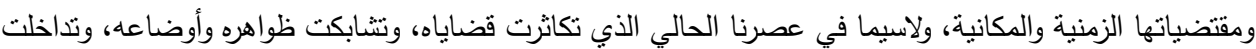
مصالحه وحاجياته، وليس لذلك من سبيل سوى جعل المقاصد إطارا جامعا بيتجيب لكل منطلبات الحياة المعاصرة.

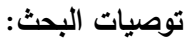

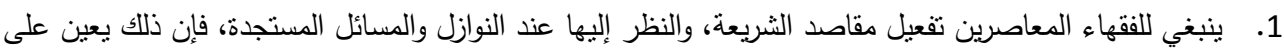
الوصول إلى الصواب الاجتهادي لتكييف هذه المستجدات بدون إسراف ولا إجحاف.

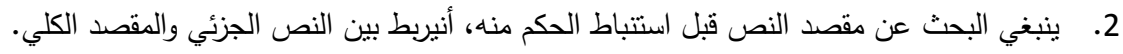
3. نشر ثقافة الفقه المقاصدي لاى طلاب العلم والدعاة إلى الله تعالى؛ لتحقيق التوازن والاعتدال في تصوراتهم وتصرفاتهم. وفي الختام، نسأله تعالى العفو عن الزلات، والتوفيق فيما هو آت؛ إنه ولي ذلك والقادر عليه سبحانه وتعالى. وصلّي اللهم على سيدنا محمد، وعلى آله وصحبه أجمعين.

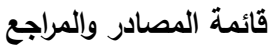

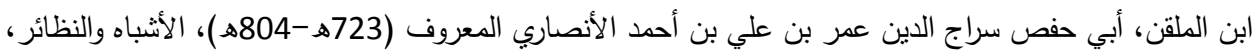

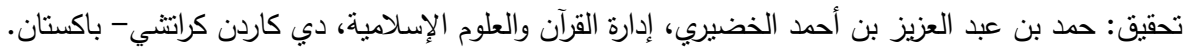

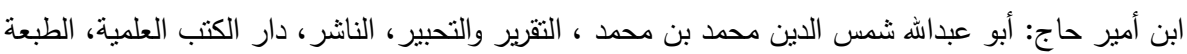
الثانية_1403هـ - 1983م.

ابن حمدان، أبو عبداله أحمد بن حمدان بن شبيب، صفة الفتوى والمفتي والمستفتي، تحقيق: محمد ناصر الدين الألباني، الناشر : المكتب الإسلامي - بيروت - الطبعة الثالثة 1397هـ. ابن سيده، أبو الحسن علي بن إسماعيل (ت:458هـ)، المحكم والمحيط الأعظم، ط1، تحقيق: عبد الحميد هنداوي، دار الكتب العلمية، بيروت، 1421هـ. ابن عاشور، محمد الطاهر (1432هـ-2011م)، مقاصد الثريعة الإسلامية، ط3، تحقيق: محمد الطاهر الميساوي، دار النفائس، عمان. 
6. ابن منظور، جمال الدين ابن منظور الأنصاري الرويفعي الافريقي، (ت: 711هـ)، حمد بن مكرم بن علي، لسان

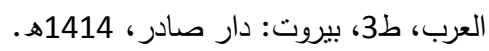

ابن نجيم، زين الدين بن إبراهيم بن محمد، الأثباه والنظائر والنظائر على مذهب أبي حنيفة النعمان، وضع إنع حواثيه

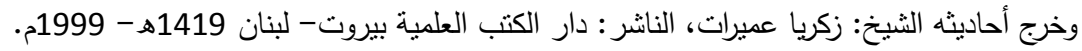

8. اطفيش، محمد بن يوسف ، شرح النيل وشفاء العليل، مكتبة الإرشاد، جدة، دار الفتح، بيروت.

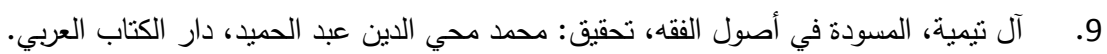

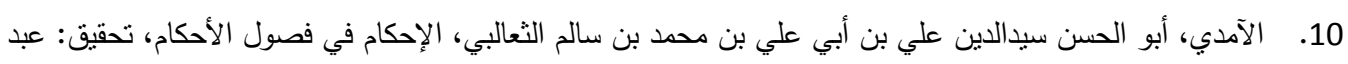

الرزاق عفيف، الناشر : المكتب الإسلامي بيروت- لبنان.

الباحسين، يعقوب بن عبد الوهاب بن يوسف الباحسين، التخريج عند الفقهاء والأصوليين سـراسة نظرية تطبيقية

تأصيلية، مكتبة الرشد، 1414هـ

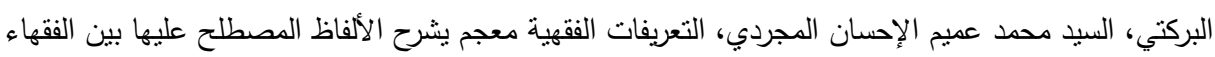

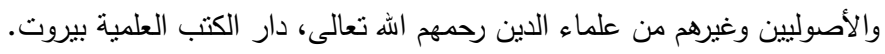

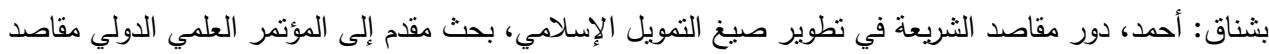

الثريعة وتطبيقاتها المعاصرة، جامعة البرموك وجامعة العلوم الإسلامية العالمية، عمان - الأردن.

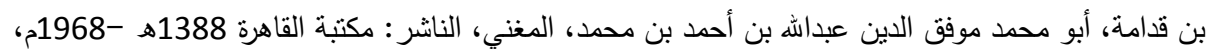

$.193 / 4$

البيهقي، أحمد بن الحسن بن علي بن موسى الخسروجودي الخراساني أبو بكر (ت:458هـ)، السنن الكبرى، ط3،

تحقيق: محمد عبد القادر عطا، دار الكتب العلمبة، بيروت، 1424هـ-2003م.

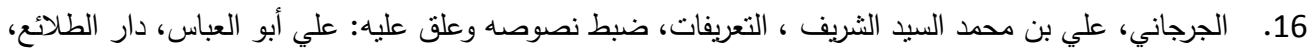

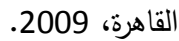

الجوهري، أبو نصر إسماعيل بن حماد، الصحاح ناج اللغة وصحاح العربية، نحقيق:أحمد عبدالغفور عطار ، دار

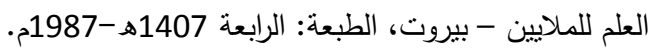

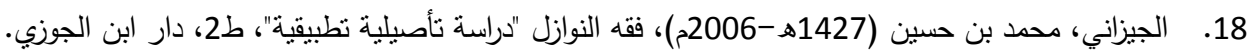

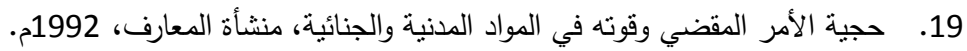

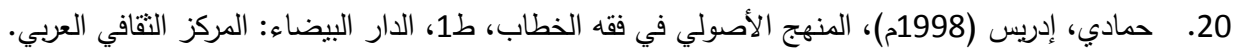

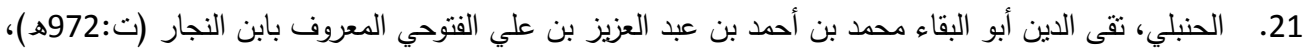

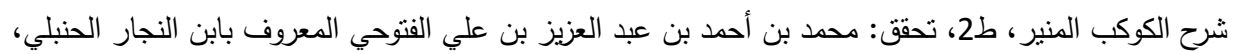
1418هـ -1997م

الحنبلي، علاء الدين أبو الحسن علي بن سليمان المرداوي الدمثقي الصالحي (ت:885هـ)، الإنصاف في معرفة

الراجح من الخلاف، ط2، دار إحياء التراث العربي.

الخادمي، نور الدين بن مختار (1419هـ-1998م)، الاجتهاد المقاصدي -حجيته- ضوابطه- مجالاته، ط1، وزارة

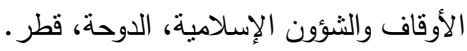

الخفيف، علي الخفف، بحوث ومقالات في التشريع الإسلامي، دار الفكر العربي، القاهرة، الطبعة الأولى، 1431هـهـ -

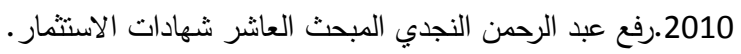




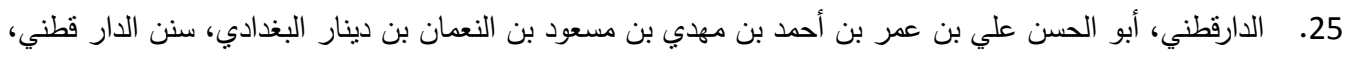

حققه وضبط نصاه وعلق عليه: شعيب الارنؤوط، حسن عبدالمنعم شلبي، عبداللطيف حرزاله، أحمد برهوم، الناشر :

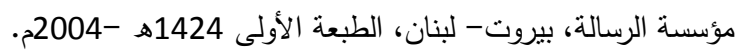

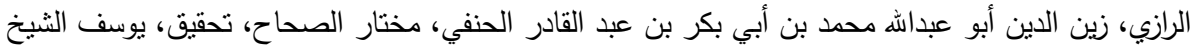

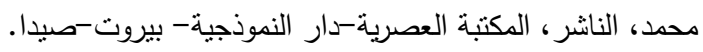

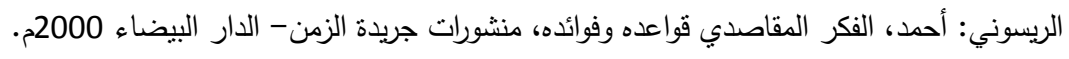

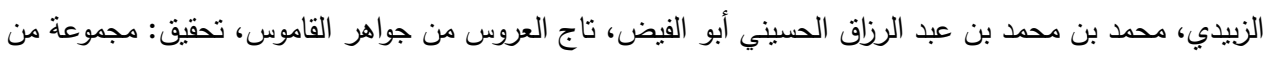

المحققين،الناشر :دار الهاية.

الزحيلي، وهبة الزحيلي، أصول الفقه الإسلامي، دار الفكر للطباعة والتوزيع والنشر - دمشق، الطبعة الأولى 1406هـ

السبكي، تقي الدين أوالحسن علي بن عبد الكافي، الإبهاج في شرح المنهاج، (منهاج الوصول إلى علم الأصول

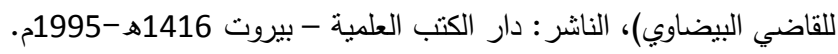

سليمان ناصر ، ربيعة بن زيد: إدارة مخاطر الصكوك الإسلامية دراسة تطبيقية على الصكوك الحكومية السودانية،

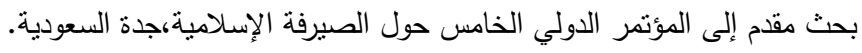

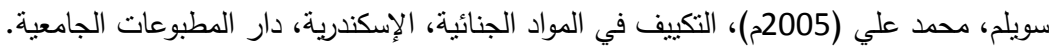

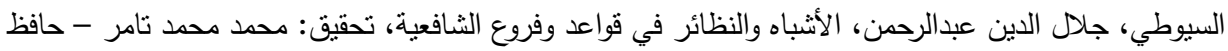

عاشور حافظ، طبعة: دار السلام.

السيوطي، عبد الرحمن بن أبي بكر جلال الدين (ت:و11هـ)، معجم مقاليد العلوم في الحدود والرسوم، ط1، مكتبة

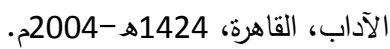

الثاطبي، إبراهيم بن موسى بن محمد اللخمي الغراناطي الثهير (ت:790هـ)، الموافقات، ط1، تحقق: ابو عبيدة

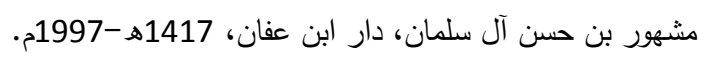

الثبير : محمد عثمان ،المعاملات المالية المعاصرة في الفقه الإسلامي، الناشر : دار النفائس، ط6 بـ 1417 1427هـ -

الثبير ، محمد عثمان (1435هـ -2014م)، التكييف الفقهي للوقائع المستجدة وتطبيقاته الفقهية، ط2، دمشق: دار

شوشان، عثمان ابن محمد الأخضر (1419هـ -1998م)، تخريج الفروع على الأصول - دراسة تاريخية ومنهجية

وتطبيقية، ط1، دار طيبة للنشر والتوزيع، السعودية.

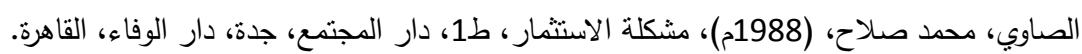

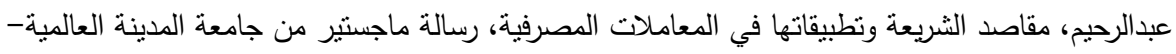

ماليزيا2012م.

العتيبي، غازي بن مرثد بن خلف، مكملات مقاصد الثريعة، تأصيلاً وتطبيقاً على بعض المسائل المعاصرة، مركز

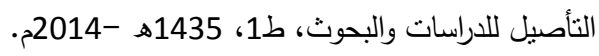

عمر عبداله كامل، القواعد الفقهية الكبرى وأثرها في المعاملات المالية، أطروحة دكتوراه غير منشورة، جامعة الأزهر 


$$
\begin{aligned}
& \text { 43. الغزالي، أبو حامد محمد (ت:505هـ)، المستصفى، ط1، تحقيق: محمد عبد السلام عبد الثافي، دار الكتب العلمية، } \\
& \text { بيروت، 1413هـ -1993م. } \\
& \text { 44. الفاسي، علال ، مقاصد الشريعة الإسلامية ومكارمها، ط5، دار الغرب الإسلامي، 1993م. } \\
& \text { 45. الفيروزآبادي، مجد الدين أبو الطاهر محمد بن يعقوب ، القاموس المحيط، تحقيق: مكتب التراث في مؤسسة الرسالة، } \\
& \text { إثراف: محمد نعيم العرقسوس. } \\
& \text { 46. الفيومي، أحمد بن محمد بن علي الفيومي ثم الحموي أبو العباس، المصباح المنير في غريب الثرح الكبير، الناشر } \\
& \text { المكتبة العلمية - بيروت. } \\
& \text { 47. القحطاني، مسفر بن علي بن محمد، منهج استتباط أحكام النوازل الفقهية المعاصرة، رسالة دكتوراة جامعة أم القرى، } \\
& \text { م } 2000 \text { - 1421 } \\
& \text { 48. قلعه جي، معجم لغة الفقهاء، محمد رواس قلعجي، حامد صادق قتيبي، دار النفائس ط2، } 1988 . \\
& \text { 49. مجمع اللغة العربية، المعجم الوجيز، ط1، 1400هـ -1980م. } \\
& \text { 50. مجموع قرارات مجامع اللغة العربية. } \\
& \text { 51. المرصفاوي، د.حسين المرصفاوي، الدعوى المدنية أمام الحاكم الجنائية، دار المعارف، 1964م. } \\
& \text { 52. المزيني: خالد بن عبداله بن علي، الفتيا المعاصرة دراسة تطبيقية في ضوء السياسة الثرعية، دار بن الجوزي، ط1، } \\
& \text { 1430هـ . } \\
& \text { 53. المناوي، عبدالرؤوف، التوفيق على مهمات التعاريف، تحقيق عبد الحميد صالح حمدان، ط1، 1990م، عالم الكتاب، } \\
& \text { 54. الموسى، عبداله بن إبراهيم، (1431هـ -2010م)، التكييف الفقهي للنازلة وتطبيقاته المعاصرة. } \\
& \text { 55. الهويريني: وائل بن عبد اله بن سليمان، المنهج في استتباط أحكام النوازل، مكتبة الرشد ناشرون، ط2، 1433هـ - } \\
& \text {.2012 } \\
& \text { هيئة المحاسبة والمراجعة للمؤسسات المالية الإسلامية، المعايير الثرعية للمؤسسات المالية الإسلامية،2007. }
\end{aligned}
$$

\section{References}

1. Ibn al-Mulaqan. Abi Hafs Siraj al-Din Omar bin Ali bin Ahmed Al Ansari Al Ma'rof. "Analogues and isotopes". Investigtion: Hamad bin Abdulaziz bin Ahmed Al Khudairy, Karachi: Department of Quran and Islamic Sciences.

2. Ibn Amir Haj, Abu Abdullah Shams al-Din Muhammad bin Mohammed (1403 e-1983) "Report and Al-inba". E. 2. Beirut: Scientific Book House.

3. Ibn Hamdan. Abu Abdullah Ahmed bin Hamdan bin Shabib. (1397 e). "Fatwa, Mufti and Mustfti describtion." Investigation: Mohammad Nasir al-Din al-Albani. E3. Beirut: Islamic Office.

4. Ibn Sidah,The son of his master, Abu Hassan Ali bin Ismail. (1421 e). "Arbitrator and the Great Ocean". Investigation: Abdul Hamid Hindawi. E1. Beirut: Scientific Book House.

5. Ibn Ashour, Muhammad al-Taher ibn Muhammad al-Taher (1984). "Liberation and Enlightenment". Tunisia: Tunisian Publishing House. 
6. Ibn Manzoor, Gamal al-Din Ibn Manzoor al-Ansari al-Ruwaifi, Hamed bin Makram bin Ali. (1414 e) "the tongue of the Arabs". E3, Beirut: Dar Sader.

7. Ibn Najim, Zayn al-Din bin Ibrahim bin Mohammad (1419 e-1999) "The analogies and isotopes on the doctrine of Abu Hanifa Numan." His ears were put out and his conversations came out Sheikh: Zakaria Amiraat. Beirut: Scientific Book House.

8. Atefish, Mohammad Ben Youssef, Sharh El Nil and Shefaal Al-Aalil, Al-Irshad Library, Jeddah, Dar Al-Fath, Beirut.

9. Al-Taymiyyah, "The Draft in the Principles of Jurisprudence". Investigation: Mohammed Muhyiddin Abdul Hamid. Arabic Book House.

10. Al-Amedi, Abu al-Hassan Sayyid al-Din Ali bin Abi Ali bin Mohammed bin Salem alTha'aliby. "Clinch in the assets of the provisions". Investigation: Abdel Razzaq Afif, Beirut: Islamic Office.

11. Al-Bahisin, Yacoub bin Abdul Wahab bin Yusuf Al-Bahisin, progression by the jurists and fundamentalists - the study of the theory of applied originality, Al-Roshd Library, $1414 \mathrm{e}$.

12. Al-Barqati, Mr. Mohammad Amim Al-IHsan Al-Majradi, "Jurisprudence Definitions" is a lexicon that explains the terms used by jurists, fundamentalists and other religious scholars, may Allah have mercy on them. Beirut: Scientific Book House.

13. Beshnaq: Ahmad, The role of the purposes of Sharia in the development of Islamic finance formulas, research presented to the International Scientific Conference the purposes of Sharia and its contemporary applications, Yarmouk University and the University of Islamic International Sciences, Amman - Jordan.

14. Ibn Qudamah, Abu Muohammad Mowaffaq al-Din Abdullah bin Ahmed bin Mohammad, Almoghni, Publisher: Cairo Library 1388 H-1968, 4/193.

15. Al-Bayhaqi, Ahmad ibn al-Hasan ibn Ali ibn Musa al-Khasrojodi, Kharasani Abu Bakr. (1424 H-2003) "Grand Sunan". Investigation: Mohammad Abdul Qader Atta. E. 3. Beirut: Scientific Book House.

16. Al-Jarjani, Ali bin Mahammad al-Sayyid al-Sharif, "Definitions", edited and commented on: Ali Abu al- Abbas, Dar Al-Talai, Cairo, 2009.

17. Al-Jawhari, Abu Nasr Ismail bin Hammad. (1407 H - 1987) "Al-Sehah Taj Al-Logha and Sehah Al-Arabia". Investigation: Ahmed Abdul Ghafour Attar.E4 Beirut: Dar Al-Ilm for millions. 
18. Al-Jizani, Muhammad bin Hussein (1427 H-2006), jurisprudence of the principles of "applied methodological study", E 2, Dar Ibn al-Jawzi.

19. "The Authenticity of the Order and its Power in Civil and Criminal Matters" (1992). Knowledge facility.

20. Hammadi, Idris (1998), "The Fundamental Approach to Fiqh Jurisprudence". E.1, Casablanca: Arab Cultural Center.

21. Al-Hanbali, Taqi al-Din Abu al-Baqa Mohammad bin Ahmad bin 'Abd al-'Aziz bin Ali alFathouhi, known as Ibn al-Najjar (d. 972), Explanation of the planet Mounir, E 2, verification: Mohammed bin Ahmed bin Abdul Aziz bin Ali al-Fotouhi known as Ibn alNajjar al-Hanbali, 1418 e-1997.

22. Al-Hanbali, Alaeddin Abul-Hassan Ali Bin Sulaiman Al-Mardawi Al-Damshqi Al-Salhi (v. 885), Al-Insaf in the knowledge of the most correct of the dispute. E2, House of Revival of Arab Heritage.

23. Al-Khadmi, Nur al-Din bin Mukhtar (1419 AH-1998), ljtihad al-Maqasdi - Hajjiyeh Controls - Fields, E1, Ministry of Awqaf and Islamic Affairs, Doha, Qatar.

24. Al-Khafef, Ali al- Khafef. (1431 H-2010). "Research and Articles in Islamic Legislation". E.1. Cairo: Arab Thought House. Abdul Rahman Al-Najdi, the tenth subject of certificates of investment.

25. Al-Dar-Qutni, Abu al-Hasan Ali ibn Omar bin Ahmed bin Mahdi bin Masood bin al-Nu'man bin Dinar al-Baghdadi. (2004). "Sunan al-Dar Qutni". Investigate and adjust the text and commented on: Shoaib Arnaout, and others. E1. Beirut: Al-Risalah Foundation.

26. Al-Razi, Zinedine Abu Abdullah Muhammad bin Abi Bakr bin Abdul Qader Hanafi. "Mukhtar al-Sahah". Investigation: Yusuf Mohammed, Beirut: Modern Library.

27. Al-Risouni: Ahmad, Al-Maqasidi Thought, Rules and Benefits, Al-Zaman Journal, Casablanca 2000.

28. Al-Zubaidi, Mohammad bin Mohammad bin Abdul Razzaq al-Husseini Abu al-Fayd. "Bride crown of jewels dictionary" Investigation: A group of investigators. House of guidance.

29. Al-Zuhaili, Wahba al-Zuhaili. (1406H- 1986.) "Principles of Islamic Jurisprudence".E.1.Damascus: Dar al-Fikr for printing, distribution and publishing.

30. Al-Sobki, Taqi al-Din Abu al- Hasan al-Hasan Ali bin Abd al-Kafi. (1416 e-1995). "Al- Ebhaj in explaining the curriculum." Beirut: Scientific Book House. 
31. Sulaiman Nasser, Rabia Bin Zaid: Risk Management of Islamic Sukuk. An Empirical Study on Sudanese Government Instruments, Presented to the Fifth International Conference on Islamic Banking, Jeddah, Saudi Arabia.

32. Suwailem, Mohammad Ali (2005), Adaptation in Criminal Materials, Alexandria, University Publications House.

33. Al-Suyuti, Jalaluddin Abdul Rahman. "The analogies and isotopes in the rules and branches of the Shaafa'is." Investigation: Mohammad Tamer - Hafez Ashour Hafez. Dar Assalam.

34. Al-Suyuti, Abdul Rahman bin Abi Bakr Jalaluddin (1424 AH-2004), "Glossary of Sciences in borders and drawings". E1. Cairo: Library of Arts.

35. Al-Shatby, Ibrahim bin Musa bin Mohammad al-Lakhmi al-Gharanati al-shahip (1417 e1997). "Approvals". investigation: Abu Ubaida Mashhour bin Hassan Al Salman.E.1. House of Ibn Affan.

36. Al-Shubair: Mohammad Othman, Contemporary Financial Transactions in Islamic Jurisprudence, Publisher: Dar Al-Nafais, Sixth Edition, 1427H -2007.

37. Al-Shubair, Mohammad Othman (1435 H -2014 AD), "The Adaptation of Fiqh to the Emerging Facts and its Applications of Jurisprudence". E2. Damascus: Dar Al-Qalam.

38. Shushan, Othman Ibn Mohammad al-Akhdar (1419 AH-1998). "Graduation of branches on assets" - a historical, methodological and applied Study. E.1.Saudi Arabia: Dar Taiba for Publishing and Distribution.

39. Al-Sawy, Mohammad Salah, (1988), the problem of investment, E 1, community house, Jeddah, Dar Al Wafa, Cairo.

40. Abdulrahim, Makassed Al Shariah and its Applications in Banking Transactions, Master Thesis from Madina International University, Malaysia, 2012.

41. Al-Otaibi, Ghazi bin Murshid bin Khalaf, Makassed Al-Shariah supplementation, the introduction and application of some contemporary issues, Al-Taasil Center for Studies and Research, first edition 1435 H-2014.

42. Kamel, Omar Abdullah. "Great Jurisprudence Rules and their Impact on Financial Transactions". Ph.D. Cairo: Faculty of Arabic and Islamic Studies, Cairo, Al-Azhar University.

43. Al-Ghazali, Abu Hamed Mohammed. (1993-1993). "Al-Mustasfa". Investigation: Mohammad Abdus Salam Abdus Shafi. E.1. Beirut: Scientific Book House.

44. Al-Fassi, Alal, Makassed of Islamic Law and Makarem, E 5, Dar al-Gharb al-Islami, 1993. 
45. Farouzabadi, Majd al-Din Abu Attahir Muhammad bin Ya`qub, Ambient Dictionary, Investigated by: The Heritage Office at Al-Resala Foundation, supervised by: Mohamed Naeem Al-Erqasus.

46. Fayoumi, Ahmed bin Mohammad bin Ali al-Fayoumi and then al-Hamawi Abu al-Abbas. "The illuminating lamp in the strange great explanation." Beirut: Scientific Library.

47. Al-Qahtani, Musfer bin Ali bin Mohammad (1421 - 2000). "Method of the development of the provisions of jurisprudential contemporary". University of Umm Al - Qura Thesis.

48. Qala'a gee, Mohammed Rawas, Hamed Sadeq Qutaibi. (1988). "Dictionary of the language of scholars". E2. House of Appreciation.

49. Arabic Language Complex, Lexicon. E1. 1400 AH -1980 AD.

50. Total resolutions of the Arabic Language Councils.

51. Al-Marsfawi, Hussein (1964). "Civil Case before the Criminal Governor", Dar Al Ma'arif.

52. Al-Muzaini: Khalid bin Abdullah bin Ali, Contemporary Fatimid Applied Study in the Light of Shariah Policy, Publisher: Dar Al-Jawzi, First Edition (1430 AH).

53. Al-Manawi, Abdul Raouf (1990). "Reconciling the tasks of definitions". E1. Investigation: Abdul Hamid Saleh Hamdan. Cairo: World of the Book.

54. Al-Mousa, Abdullah bin Ibrahim. (1431 H-2010), "the adaptation of the jurisprudential of AINazelh and contemporary applications." Publications: Imam Muhammad bin Saud University.

55. Hawairini, Wael bin Abdullah bin Suleiman. (1433 H -2012). "The method in devising the provisions of Annawazel". E2. Al - Roshd Library Publishers.

56. Accounting and Auditing Organization for Islamic Financial Institutions, Shariah Standards for Islamic Financial Institutions, 2007. 